FEDERAL RESERVE BANK OF SAN FRANCISCO

WORKING PAPER SERIES

\title{
The Effects of Quasi-Random Monetary Experiments
}

\author{
Oscar Jorda \\ Federal Reserve Bank of San Francisco \\ Moritz Schularick \\ University of Bonn and CEPR \\ Alan M. Taylor \\ University of California, Davis \\ NBER, and CEPR \\ May 2018 \\ Working Paper 2017-02
}

http://www.frbsf.org/economic-research/publications/working-papers/2017/02/

\section{Suggested citation:}

Jorda, Oscar, Moritz Schularick, Alan M. Taylor. 2018. “The Effects of Quasi-Random Monetary Experiments” Federal Reserve Bank of San Francisco Working Paper 2017-02. https://doi.org/10.24148/wp2017-02

The views in this paper are solely the responsibility of the authors and should not be interpreted as reflecting the views of the Federal Reserve Bank of San Francisco or the Board of Governors of the Federal Reserve System. 


\title{
The effects of quasi-random monetary experiments *
}

\author{
Òscar Jordà ${ }^{+}$
}

\author{
Moritz Schularick $\ddagger$
}

April 2018

\author{
Alan M. Taylor $\S$
}

\begin{abstract}
The trilemma of international finance explains why interest rates in countries that fix their exchange rates and allow unfettered cross-border capital flows are largely outside the monetary authority's control. Using historical panel-data since 1870 and using the trilemma mechanism to construct an external instrument for exogenous monetary policy fluctuations, we show that monetary interventions have very different causal impacts, and hence implied inflation-output trade-offs, according to whether: (1) the economy is operating above or below potential; (2) inflation is low, thereby bringing nominal rates closer to the zero lower bound; and (3) there is a credit boom in mortgage markets. We use several adjustments to account for potential spillover effects including a novel control function approach. The results have important implications for monetary policy.

JEL classification codes: E01, E30, E32, E44, E47, E51, F33, F42, F44
\end{abstract}

Keywords: interest rates, monetary experiments, trilemma, fixed exchange rates, instrumental variables, local projections, local average treatment effect

${ }^{\star}$ Comments and suggestions from James Cloyne, Julian di Giovanni, Gernot Müller, Ricardo Reis, and Jón Steinsson have helped improve the paper. We are grateful to Helen Irvin for outstanding research assistance. We thank James Cloyne and Patrick Hürtgen for sharing their data with us. Seminar and conference participants at Ohio State University, the Board of Governors of the Federal Reserve, the Federal Reserve Bank of Chicago, the Federal Reserve Bank of San Francisco, the Federal Reserve Bank of Cleveland, the Fourth CEPR Economic History Symposium, De Nederlandsche Bank, the Bank of England, the 23rd Dubrovnik Economic Conference, the 7th Joint Bank of Canada and European Central Bank Conference, the NBER Impulse and Propagation Mechanisms meeting, and the NBER Monetary Economics meeting provided useful feedback. All errors are ours. Generous support from the Institute for New Economic Thinking, the Bundesministerium für Bildung und Forschung (BMBF), and the Volkswagen Foundation supported different parts of the data collection and analysis effort. We are grateful for their support. The views expressed in this paper are the sole responsibility of the authors and do not necessarily reflect the views of the Federal Reserve Bank of San Francisco or the Federal Reserve System.

${ }^{\dagger}$ Federal Reserve Bank of San Francisco; and Department of Economics, University of California, Davis (oscar.jorda@sf.frb.org; ojorda@ucdavis.edu).

‡Department of Economics, University of Bonn; and CEPR (moritz.schularick@uni-bonn.de).

\$Department of Economics and Graduate School of Management, University of California, Davis; NBER; and CEPR (amtaylor@ucdavis.edu). 



\section{INTRODUCTION}

Three features characterize the history of advanced economies in the past 20 years: (1) a dramatic credit boom and bust; (2) unusually low and stable inflation throughout; and (3) a prolonged period of below potential growth following the Global Financial Crisis. Given this background, we investigate whether or not (1) periods of high credit growth make contractionary policy a more forceful policy tool (2) monetary policy is less stimulative when inflation is low (and hence nominal rates closer to the zero lower bound); and (3) monetary policy is more effective when the economy is above potential. Answers to these questions have important implications for monetary policy and for models of monetary economies.

It is largely an empirical matter to determine how useful a cyclical stabilizer monetary policy is. However, empirical measures of the effect of interest rates on macroeconomic outcomes are fraught. Macroeconomic aggregates and interest rates are jointly determined since monetary policy reflects the central bank's policy choices given the economic outlook. In the parlance of the policy-evaluation literature (see, e.g., Rubin, 2005), any measure of the treatment effect of policy is contaminated by confounders simultaneously correlated with the treatment assignment mechanism and the outcome.

Over time, several best-practice methods have emerged, but almost all are exclusively based on the Post-WW2 U.S. experience. The general theme running through the literature is to control for information that might explain the policymaker's choices. Some of this control is explicit (along with additional exclusion restrictions) such as the venerable literature based on vector autoregressions or VARs (see, e.g., Christiano, Eichenbaum, and Evans, 1999). Romer and Romer (1989) infer exogenous policy shifts from the narrative of the policy record though what may look like a surprise in the minutes may not have been a surprise to the policymaker.

Continuing in this vein, Romer and Romer (2004), Cloyne and Hürgten (2016) and Coibion et al. (2017) measure policy surprises by assuming that policymakers rely only on their staff's forecasts to choose policy. Taking a different approach, Kuttner (2001), Faust, Wright, and Swanson (2004), Gertler and Karadi (2015), and Nakamura and Steinsson (forthcoming) instead appeal to the efficiency of financial markets. A surprise change in policy rates inferred from high-frequency asset price reactions in a short window may then serve as a natural proxy for exogenous policy movements, though what surprised the market may not have surprised the policymaker.

This paper proposes a different approach based on a quasi-natural experiment. How a country manages its exchange rate and how freely capital flows across its borders has direct implications for its domestic interest rates, and hence for monetary policy. This is especially true for safe assets with low liquidity and risk premiums, such as government securities and interbank credit.

Consider such assets which, though denominated in different currencies, are otherwise perfect substitutes. Assume their currencies are credibly pegged for the duration of the investment and that investors can freely transfer funds. Then, without exchange rate risk, arbitrage would equalize the rates of return across all markets. Economic forces thus limit a country's policy choices with respect to the triad of capital mobility, exchange rates, and interest rates. The trilemma faced by policymakers 
is that they can have control over two out of the three policies, but not all three simultaneously. Articulating how and when the trilemma functions as a source of natural experiments in domestic monetary policy is one of the contributions of this paper.

The general empirical validity of the trilemma, in both recent times and in distant historical epochs, has been recognized for more than a decade: exogenous base country interest rate movements spill into local interest rates for open pegs (Obstfeld, Shambaugh, and Taylor 2004, 2005; Shambaugh 2004). ${ }^{1}$ Some important corollaries directly follow for empirical macroeconomics. A key contribution by di Giovanni, McCrary, and von Wachter (2009) exploits the resulting identified local monetary policy shocks to estimate impulse response functions for other macroeconomic outcome variables of interest using standard VAR methods with instrumental variables. ${ }^{2}$

In this paper we take these ideas further. Variation in base rates can be used as a natural experiment, but only by appropriately sorting the different channels of trilemma transmission. We do this by extending the lessons from the policy evaluation literature and identification with instrumental variables (IV) to a time series setting using local projections (Jordà 2005).

Instrumental variable applications using local projections (LP-IV) have recently appeared in a variety of settings (see, e.g., Jordà, Schularick, and Taylor 2015; Ramey and Zubairy 2017; Stock and Watson 2017). Here we expand the sample from the commonly studied post-WW2 period in the U.S., and include now all of advanced economy macroeconomic history since 1870. Our results are thus based on a much larger cross-sectional sample spanning over a century and are therefore important in that they bring greater statistical power to robustly validate and generalize extant findings based hitherto on the U.S. post-WW2 data alone.

Our main findings are easily summarized. First, using the subpopulation of open pegs, we find evidence of considerable attenuation bias in policy responses when we estimate the responses to monetary policy using traditional OLS selection-on-observables identification versus instrumental variables identification. Second, we investigate the robustness of our new IV estimates for open pegs as compared to the effects found by investigating the combined behavior of post-WW2 data from the U.S. and U.K. using the established approaches of Romer and Romer (2004) and Cloyne and Hürtgen (2016).

Third, we take several steps to control for spillover confounding (or failure of the exclusion restriction), such as accounting for global business cycle effects, and working with base country policy surprises rather than directly with interest rates. However, we go one step further. We discuss a novel approach to assess spillover confounding using control functions (see Wooldridge 2010; Conley, Hansen, and Rossi 2012) and by taking advantage of the subpopulations that make up our data. Although it might appear obvious which way this bias goes, careful calculation shows that its direction is ambiguous. Guided by economic reasoning, we place plausible bounds on this bias and

\footnotetext{
${ }^{1}$ Open pegs are countries that fix their exchange rate but allow relatively free movement of capital.

${ }^{2}$ In related work, di Giovanni and Shambaugh (2008) used the trilemma to investigate post-WW2 output volatility in fixed and floating regimes. Ilzetzki, Mendoza, and Végh (2013) partition countries by exchange rate regime to study the impact of a fiscal policy shock. In previous work (Jordà, Schularick, and Taylor 2015), we studied the link between financial conditions, mortgage credit, and house prices.
} 
show that this source of confounding, if anything, tends to reinforce our main findings.

We can also connect our empirical findings to recent theoretical developments that examine the efficacy of monetary policy as a function of (household and/or firm) leverage. For example, Auclert (2017) shows that the effectiveness of monetary policy depends on household balance sheet exposure through the redistributive channels that interest rates can have. In Kaplan, Moll, and Violante (2017), the mechanism operates via the heterogeneity in marginal propensities to consume of households facing uninsurable income shocks in incomplete markets. Narrowing the focus, Iacioviello (2005) and Cloyne, Ferreira, Surico (2015) argue that households' reactions to monetary policy shocks varies depending on variation in levels of mortgage indebtedness. We show that mortgage booms indeed have strong effects on the policy trade-off that are consistent with this literature.

On the firm side, a venerable literature (Bernanke and Gertler 1995; Kashyap, Lamont, and Stein 1994; Kashyap and Stein 1995) has argued that credit constrained firms are more responsive to monetary policy. More recently, Ottonello and Winberry (2017) focus on firm (credit) heterogeneity to investigate asymmetry in the investment channel of monetary policy. In contrast to our earlier findings on mortgage credit, we find little evidence of asymmetries related to firm-side credit growth.

We also find-like others before us-that one source of state dependence comes from how the economy responds to monetary policy in the boom versus the slump. Specifically, we find that stimulating a weak economy is much harder than reining in a strong one. Yet another source of state dependence comes from the level of inflation, however. Advanced economies have recently struggled with a low-growth, low-inflation environment, referred to by commentators as "lowflation." The historical data show that monetary policy turns out to be rather ineffective in lowflation environments, thus revealing another hitherto unexamined dimension in which monetary policy is asymmetric. Perhaps this is not surprising as episodes where inflation is very low are usually associated with nominal rates close to the zero lower bound, effectively limiting the available monetary policy space.

This paper thus makes a number of contributions to monetary economics and to empirical macroeconomics broadly speaking. On average, monetary policy has strong and long-lasting effects, consistent with results from the recent literature. However, monetary policy effects can vary greatly with the state of the economy, and that state may depend on a rich set of characteristics, including the business cycle, inflation, and leverage. All of these findings matter when drafting theoretical models of monetary economies. In terms of empirical methods, we are careful to spell out, in a dynamic local projection framework, the crucial instrumental variable identification assumptions and how they might be valid for some subpopulations but not for others. Moreover, we introduce methods to provide well-reasoned bounds on potential biases coming from untestable failures of the instrumental variables exclusion restriction. All of these new developments should provide for a tighter link with long-standing policy evaluation methods in applied microeconomics and bring empirical macroeconomics closer to a unified protocol for data analysis. 


\section{THE TRILEMMA OF INTERNATIONAL FINANCE:}

\section{A QUASI-NATURAL EXPERIMENT}

In open economies, exchange rates, capital flows, and monetary policy—and, thus, their managementare all intertwined. The observation that countries cannot simultaneously control all three of these policy components is known as the trilemma of international finance (see, e.g., Obstfeld and Taylor 1998, 2004; Obstfeld, Shambaugh, and Taylor 2004, 2005; Shambaugh 2004).

Due to the trilemma, there are situations where external conditions can generate exogenous fluctuations in monetary policy. Inspired by this observation, at times the literature has used short-term or central bank interest rates from major center economies as either exogenous shocks or as instruments for domestic interest rates in noncenter countries. To take an example, di Giovanni, McCrary, and von Wachter (2009) estimate the effect of monetary policy for twelve noncenter European countries in the ERM system with a VAR and by using German center-country rates as an instrument in an era of capital mobility and pegged exchange rates.

Here, due to the broader and richer historical context we study, we must separately consider each of the three components of the trilemma to construct our instrument: (1) the choice of exchange rate regime; (2) the degree of capital mobility; and (3) the interest rate of the base country. Moreover, rather than directly using the base country interest rate, we first sterilize the predictable component that could be explained by economic conditions in the base country. The specific construction of the resulting instrumental variable, and the manner in which the analysis is designed around it, sets our paper apart from the literature.

An international dimension is obviously critical for our analysis. So is having a long time series to observe variation of the trilemma policy components over time. Our analysis therefore relies on our previous work (Jordà, Schularick, and Taylor 2017). In particular, the data that we use covers real and financial data for 17 advanced economies at annual frequency from 1870 to $2013 .{ }^{3}$ Unlike the majority of empirical papers in monetary economics, which tend to rely on post-WW2 U.S. data, our analysis rests both on a long time dimension and a large group of countries.

\subsection{Defining the base country in fixed exchange rate regimes}

As the first step in constructing the instrumental variable, we note that the trilemma naturally breaks the data down into the three subpopulations. First, there is the group of base countries whose currency serves as the focal anchor for pegging economies. The latter, the group denoted the pegs, then form the second of our subpopulations. The remaining economies, which allow their currency to be determined freely in the market, is the group we call the floats, the third subpopulation. This subsection discusses the construction of the base subpopulation.

3These are: Australia, Belgium, Canada, Denmark, Finland, France, Germany, Italy, Japan, Netherlands, Norway, Portugal, Spain, Sweden, Switzerland, U.K. and U.S. The data and detailed descriptions are available at http://www.macrohistory.net/data. 
Table 1: Selection of base country short-term interest rate for pegged exchange rates by era

\begin{tabular}{lcccc}
\hline \hline & \multicolumn{2}{c}{ Home country interest rates associated with the base country } \\
\cline { 2 - 4 } Base country interest rate & Pre-WWi & Interwar & Bretton Woods & Post-BW \\
\hline UK & All & & Sterling bloc: \\
(Gold standard/BW base) & countries & & AUS* & \\
UK/USA/France composite & & All & & \\
(Gold standard base) & countries & & All other \\
USA & & countries & AUS, CAN, CHE, \\
(BW/Post-BW base) & & & JPN, NOR \\
& & & All other \\
Germany & & & countries \\
(EMS/ERM/Eurozone base) & & & \\
\hline \hline
\end{tabular}

${ }^{*}$ We treat Australia as moving to a U.S. dollar peg in 1967.

Notes: See text, Jordà, Schularick, and Taylor (2015), and Obstfeld, Shambaugh, and Taylor (2004, 2005). Pre-WW1: 1870-1914; Interwar: 1920-1938; Bretton Woods: 1948-1971; Post-BW: 1972-2013.

Part of the data construction effort consists of defining the base countries for pegs across different eras. This is described in Table 1 . The possible base country interest rates used at different times in the history of exchange rate regimes correspond to the four rows in the table. The four major eras correspond to the four columns in the table. The table cells indicate which pegging countries correspond to each base in each era.

Prior to WW2, peg codings are taken from Obstfeld, Shambaugh, and Taylor $(2004,2005)$. After WW2 they are gleaned from Ilzetzki, Reinhart, and Rogoff (2008) and updates thereto. One exception with respect to this literature is that we do not code Germany as being pegged from 1999 onwards to emphasize the outsize role that Germany plays within the euro zone as a continuation of its central position with the EMS/ERM fixed exchange rate system. Prior to 1914 we treat the U.K. as the base for everyone, and after 1945 we treat the U.S. as the base for everyone, with the exception of EMS/ERM/Eurozone countries for which Germany is the base after 1973. In the interwar period, the choice of a suitable base country is more challenging and subjective given the instability of the interwar gold standard period; we follow Obstfeld, Shambaugh, and Taylor (2004) in using a hybrid "gold center" short-term interest rate, which is an average of U.S., U.K., and French short term rates depending on which of the three countries was pegged to gold in a particular year; our results are not sensitive to this choice and we replicate our findings using any one of these three countries as the sole interwar base as in Obstfeld, Shambaugh, and Taylor (2004).

Central banks of base countries, like the U.S. Federal Reserve in the Bretton Woods era, generally have paid little to no attention to economic conditions in other countries when making policy choices. Such behavior finds ample support in the historical record, as discussed in Jordà, Schularick, and Taylor (2015). Thus, to peg is to sacrifice monetary policy autonomy, at least to some degree. 
Table 2: Share of sample country-year observations where a country switches its exchange rate regime

\begin{tabular}{lcccccccc}
\hline \hline & \multicolumn{2}{c}{ Full sample } & & \multicolumn{2}{c}{ Pre-WW2 } & & \multicolumn{2}{c}{ Post-WW2 } \\
\cline { 2 - 3 } & Frequency & $\%$ & & Frequency & $\%$ & & Frequency & $\%$ \\
\hline Float to peg & 19 & 2 & & 6 & 3 & & 13 & 2 \\
No change & 954 & 96 & & 191 & 93.2 & & 763 & 97.0 \\
Peg to float & 19 & 2 & & 8 & & & & \\
Total & 992 & 100 & & 205 & 100 & & 787 & 100 \\
\hline \hline
\end{tabular}

Notes: Full sample: 1870-2013 excluding 1914-1919 and 1939-1947. Pre-WW2 sample: 1870-1938 (excluding 1914-1919). Post-WW2 sample: 1948-2013. frequency refers to the number of observations; \% is the percent of the sample in a given category. Specifically float to peg means a country went from floating to pegging its exchange rate; peg to float means the country abandoned a peg; remain means the exchange rate regime this year is the same as in the previous year. See text.

\subsection{Defining the peg and float subpopulations}

If a country is currently in a peg and it was in a peg the previous year then we define the exchange rate regime indicator $q_{i, t}=1$, otherwise $q_{i, t}=0$. This definition makes a more conservative choice to ensure that the peg is well-established before including a particular country-time pair $\{i, t\}$ when constructing the subpopulation of pegs. That is, we want to eliminate opportunistic pegging motivated by conditions that could be related to a country's monetary conditions.

Over the last 150 years countries went in and out of fixed exchange regimes. However, once in a peg, countries tend to stick to the arrangement. In contrast to Obstfeld and Rogoff (1995), who found the average duration of fixed exchange rates since 1973 to be about 5 years, we find in our longer-run sample that average to be about 21 years. Part of the reason is that our sample includes advanced economies only, whereas theirs includes emerging market economies as well. Another is that our sample includes longer-lived peg episodes in the gold standard and Bretton Woods eras.

Table 2 shows the remarkable stability of the exchange rate regimes chosen by the countries in our sample. The table reports the frequency with which a country switches from one regime to the other, and the frequency with which it retains its current arrangement. The table makes clear that switches are very infrequent, less than $5 \%$ of the sample overall, although switches were slightly more frequent before WW2 than after.

Pegging arrangements come in different shades. For example, countries sometimes allow the exchange rate to fluctuate inside a narrow band. This was the case for several European economies in the lead up to the euro. The diversity of pegging arrangements will tend to attenuate the pass-though of base rates to domestic rates the more flexible the arrangement is. In fact, we later show such an attenuation in the data. However, instrumental variable identification does not require this pass-through to be perfect. The only requirement is for there to be significant covariation in rates, which the data support. Fluctuations inside a corridor limit exchange rate variation such that wide interest rate differentials cannot persist in practice. 


\subsection{Constructing the instrument: the first stage}

We have nearly all the elements in place to construct our instrumental variable. Specifically, let $\Delta r_{i, t}$ denote the change in short-term nominal interest rates in country $i$ at time $t$, and let $\Delta r_{b(i, t), t}$ denote the short-term nominal interest in country $i$ 's base country $B$ at time $t$, which can differ across $i$ and over time-hence the notation $b(i, t)$. Both $\Delta r_{i, t}$, and $\Delta r_{b(i, t), t}$ are three-month short-term government bill or private market interest rates, the closest measure of monetary conditions that we were able to obtain consistently for our long and wide panel of historical data. 4

Next, define the variable $k_{i, t} \in[0,1]$ which indicates whether country $i$ is open to international markets or not. We base this capital mobility indicator on the index (from o to 100) in Quinn, Schindler, and Toyoda (2011). We use a continuous version of their index rescaled to the unit interval, with 0 meaning fully closed and 1 fully open. Over time, in the advanced economies we study, full international capital mobility has been notably interrupted by the two world wars. Resumption of mobility was nearly immediate after WW1. It was not so after WW2, in large part due to the tight constraints on capital movements that were central to the Bretton Woods regime. Nowadays, capital mobility is commonplace in all advanced economies.

More specifically, we find that in our data the average value of $k$ for the pegs in the full sample is 0.87 (with a standard deviation of 0.21 ) versus $0.70(0.31)$ for floats. In the post-WW2 era, these averages are virtually indistinguishable from one another, with values of $0.76(0.24)$ for pegs and 0.74 (0.30) for floats. Thus, it cannot be said that pegs on average used more restrictions on capital to regain control over monetary policy than floats, and the subsamples are balanced on this dimension. Moreover, note that it is clear that restrictions on capital mobility have not been used as a highfrequency policy tool by pegging economies since the index is very slow moving, unlike interest rate policy settings.

Finally, we denote with $\Delta \widehat{r}_{b(i, t), t}$ movements in base country $b(i, t)$ rates explained by observable controls for that base country, denoted $x_{b(i, t), t}$. Similarly, denote with $x_{i, t}$ a broad set of domestic macroeconomic controls in country $i$ at time $t$. Such controls include current and lagged values of macroeconomic aggregates, and lagged values of the policy variable. Putting all these elements together, our instrument is constructed to equal $z_{i, t} \equiv k_{i, t}\left(\Delta r_{b(i, t), t}-\Delta \widehat{r}_{b(i, t), t}\right)$ if $q_{i, t}=1$, and to equal $z_{i, t}=0$ if $q_{i, t}=0$.

Notice three features of how the instrument is constructed. First is our focus on isolating unpredictable movements in base country interest rates rather than base rates themselves. The idea is to narrow the focus to movements in base country rates that would not have been predicted using observable information by country $i .5$ Moreover, the extent to which there are external factors affecting base and pegging economies will tend to contaminate the raw measure but not its

\footnotetext{
4Swanson and Williams (2014) and Gertler and Karadi (2015) are two recent examples of papers that step back from using typical interbank overnight rates and instead measure monetary policy with government rates for bonds at a duration of up to 2-years in some cases.

${ }^{5} \mathrm{~A}$ lower standard of proof would be to use $\Delta r_{b(i, t), t}$ directly. Experiments with such an instrument produced similar results to those reported below and are available upon request.
} 
Table 3: First-stage relationship between change in short-rates for pegs and the trilemma instrument

\begin{tabular}{|c|c|c|c|c|c|c|}
\hline \multirow[t]{3}{*}{ Dependent variable: $\Delta r_{i, t}$} & \multicolumn{3}{|c|}{ No controls } & \multicolumn{3}{|c|}{ With controls } \\
\hline & (1) & (2) & (3) & (4) & (5) & (6) \\
\hline & All years & Pre-WW2 & Post-WW2 & All years & Pre-WW2 & Post-WW2 \\
\hline \multicolumn{7}{|l|}{ Pegs: $q=1$} \\
\hline$z_{i, t}$ (instrument) & $\begin{array}{c}0.58^{* * *} \\
(0.09)\end{array}$ & $\begin{array}{c}0.40^{* * *} \\
(0.09)\end{array}$ & $\begin{array}{c}0.67^{* * *} \\
(0.10)\end{array}$ & $\begin{array}{c}0.52^{* * *} \\
(0.06)\end{array}$ & $\begin{array}{l}0.35^{*} \\
(0.17)\end{array}$ & $\begin{array}{c}0.56^{* * *} \\
(0.06)\end{array}$ \\
\hline$t$-statistic & {$[6.58]$} & {$[4 \cdot 32]$} & [6.46] & {$[8.62]$} & [2.05] & [8.97] \\
\hline Observations & 1059 & 438 & 621 & 672 & 148 & 524 \\
\hline
\end{tabular}

Notes: ${ }^{* * *} p<0.01,{ }^{* *} p<0.05,{ }^{*} p<0.1$. Standard errors in parentheses. Full sample: $1870-2013$ excluding 1914-1919 and 1939-1947. Pre-WW2 sample: 1870-1938 (excluding 1914-1919). Post-WW2 sample: 1948-2013. Country fixed effects included in the regressions for columns $4-6$. These regressions also include up to two lags of the first difference in log real GDP, log real consumption, investment to GDP ratio, credit to GDP, short and long-term government rates, log real house prices, log real stock prices, and CPI inflation. In addition we include world GDP growth to capture global cycles. See text.

unpredictable component. Second, notice that we observe an important prescription of the trilemma by modulating the strength of the instrument according to the degree of capital openness, $k_{i, t}$. Third, the instrumental variable is allowed to operate only for pegs, as the trilemma dictates. These are all important innovations with respect to what has been previously attempted in the literature.

An assumption that will turn out to play a role later in our analysis is that of monotonicity. We state it here formally:

\section{Assumption 1. Monotonicity}

Let $\Delta r$ denote the indicator of domestic monetary conditions, $\boldsymbol{x}$ the vector of domestic controls, including lags of $\Delta r$, and let $z$ denote the instrument for $\Delta r$. We omit subindices for simplicity. Then we assume that in population:

$$
\frac{\partial E(\Delta r \mid \boldsymbol{x})}{\partial z} \geq 0
$$

That is, according to this assumption, if the base country raises its interest rate, on average the home country will do so too-as the trilemma suggests should be the case. This assumption is similar to the assumption of monotonicity in, for example, Angrist and Imbens (1994).

Table 3 reports first-stage regression results of the endogenous variable, $\Delta r_{i, t}$ on the instrument $z_{i, t}$, without controls in columns $1-3$, and then more formally with controls, in columns $4-6$. We do this for the subpopulation of pegs as the trilemma suggests. ${ }^{6}$ The table clearly shows that $z_{i, t}$ is not a weak instrument. Columns 4-6 refer to the formal first-stage regression with controls, country fixed effects and robust (clustered) standard errors (the regression also allows the coefficients of the controls to differ for the period 1973 to 1980 to account for the two oil crises as we also discuss

\footnotetext{
${ }^{6}$ Similar estimates for the float subpopulation are consistent with a nearly zero pass-through of base rates to domestic rates, as the trilemma suggests. They are available upon request.
} 
below). The $t$-statistic on $z_{i, t}$ is well above 3 for the full and post-WW2 samples. Moreover, notice that the slope estimates in columns $4-6$ are similar to those in columns $1-3$, which suggests that the instrument is relevant in that contains information that is quite different from that contained in the controls. 7

\section{Methods}

The central goal of our paper is to evaluate the effects of a domestic monetary policy intervention on domestic macroeconomic outcomes. Identification of the causal effect is based on an external instrumental variables (IV) approach using the trilemma discussed in the previous section. Identification depends on the exclusion restriction, in this case the assumption that base country interest rates affect peg economies only through the interest rate channel.

When the model is just identified-as ours is - the exclusion restriction is untestable. Based on how the instrument is constructed and the economics of the trilemma, we have solid justification for why the exclusion restriction holds, at least approximately. However, we also discuss a method to provide interpretable bounds on spillover effects even if the exclusion restriction were to failanother innovation of this paper relative to the literature.

We calculate these bounds by taking advantage of the float subpopulation for which the trilemma instrument is known to be invalid. The way we go about calculating such bounds it to assume the worst case scenario, that is, that any effect of base country interest rates on floating economies operates entirely through spillover effects and not through interest rate channels. We show how an estimate of this worst-case scenario spillover effect in the floats can be used to then calculate a bound for the IV estimates in the peg subpopulation, as we shall explain momentarily.

We can begin by defining the random variable $y(h)$ in reference to a macroeconomic outcome of interest observed $h$ periods from today for $h=0,1, \ldots, H-1$. For example, we may be interested in the growth rate approximation given by 100 times the log difference between real GDP in $t+h$ relative to $t$ when computing a cumulative impulse response resulting from a monetary policy intervention. We can collect all such random variables into an $H \times 1$ vector $\boldsymbol{y}=(y(0), y(1), \ldots, y(h), \ldots, y(H-1))$.

In reporting the average effects of a policy intervention over time, we will adopt the convention of normalizing the intervention to a 1 percentage point (100 bps) increase in interest rates $(\Delta r=1)$ compared to a counterfactual of leaving interest rates unchanged $(\Delta r=0)$. Further, we denote as $x$ the vector of controls which include lags of the outcome, lags of the intervention variable, and any other exogenous or predetermined variables. Moreover, we assume that the controls affect the outcome linearly for the moment.

7The control list includes up to two lags of the first difference in log real GDP, log real consumption, investment to GDP ratio, credit to GDP, short and long-term government rates, log real house prices, log real stock prices, and CPI inflation. 
Like the average treatment effect in applied microeconomics, we are interested in the impulse response given by the forecast path for the outcome variable and its counterfactual, that is:

$$
\mathcal{R}_{A T E} \equiv E(\boldsymbol{y} \mid \Delta r=1 ; \boldsymbol{x})-E(\boldsymbol{y} \mid \Delta r=0 ; \boldsymbol{x})
$$

where we note that $\mathcal{R}_{A T E}$ is a vector of dimension $H \times 1$. Notice that $\mathcal{R}_{A T E}$ could be estimated by using a vector autoregression (or VAR). For reasons that will become apparent shortly, we prefer to approximate the conditional expectations in (1) using local projections (Jordà, 2005). In particular, consider the following set of panel local projections:

$$
y_{i, t+h}=\alpha_{i, h}+\Delta r_{i, t} \beta_{h}+x_{i, t} \gamma_{h}+v_{i, t+h} ; \quad \text { for } h=0, \ldots, H-1
$$

using a longitudinal sample where $i=1, \ldots, N$; and $t=1, \ldots, T$. Expression (2) could be naïvely estimated by standard OLS panel-data methods, and we will refer such an estimate as LP-OLS. Notice that $\alpha_{i, h}$ is a fixed effect. We also note for later reference that we will include a global GDP variable to parsimoniously remove global business cycle effects. From this regression it is easy to see that $\mathcal{R}_{A T E}=\boldsymbol{\beta}=\left(\beta_{0}, \ldots, \beta_{H-1}\right)^{\prime}$.

What about causality? Under OLS, the identification of causal effects for the coefficient $\beta_{h}$ in expression (2) relies, roughly speaking, on $\Delta r$ being randomly assigned given the controls included in the regression. One way to express the conditions under which such a regression would be causally interpretable is to use the potential outcomes approach (see Rubin, 1974). Using standard notation, and in a linear setup such as ours, it would suffice to assume the following:

\section{Assumption 2. Conditional mean independence}

Let $y_{1}$ denote the random variable drawn from the distribution of potential outcomes when $\Delta r=1$-the treated subpopulation. Similarly, let $\boldsymbol{y}_{0}$ refer to potential outcomes from the control subpopulation, that is, when $\Delta r=0$. We assume that:

$$
E\left(\boldsymbol{y}_{1} \mid \Delta r=1, \boldsymbol{x}\right)=E\left(\boldsymbol{y}_{1} \mid \boldsymbol{x}\right) \quad \text { and } \quad E\left(\boldsymbol{y}_{0} \mid \Delta r=0, \boldsymbol{x}\right)=E\left(\boldsymbol{y}_{0} \mid \boldsymbol{x}\right)
$$

that is, conditional on the controls, $\boldsymbol{x}$, there is no selection mechanism that explains differences in the conditional means of the potential outcomes $\boldsymbol{y}_{1}$ and $\boldsymbol{y}_{0}$.

Put differently, given $x, \Delta r$ is as good as if it were randomly assigned. Parenthetically, this type of assumption permeates the VAR literature, although it is rarely stated like this. For example, identification based on zero short-run restrictions and Cholesky ordering is a type of conditional mean assumption. The Cholesky ordering is equivalent to calculating the conditional mean $E(\boldsymbol{y} \mid \Delta r, \boldsymbol{x})$ by including in the control vector $x$ those variables ordered first in the assumed ordering dated contemporaneously with the treatment variable $\Delta r$ in addition to their lags. However, as we show below, the data strongly reject this conditional mean assumption. For this reason we have to explore other methods to achieve identification based on the trilemma instrument that we now discuss. 


\subsection{Identification with external instruments}

Fluctuations in the unpredictable component of the base country policy rate, modulated according to the mobility of arbitrage capital across borders, induce exogenous fluctuations in the policy rate of countries that peg their exchange rate to it. This leads us to conclude that the correlation between the trilemma instrument and the policy intervention variable can thus be used to calculate a local impulse response in the sense of the local average treatment effect in Angrist and Imbens (1994). However, we need to be aware that, because the instrument does not operate for floats, causal effects can only be formally estimated for the subpopulation of pegs.

In terms of the conditions needed for our instrument to be valid, we make the usual assumptions, that is:

\section{Assumption 3. Relevance and exogeneity}

$$
\begin{array}{ll}
L(\Delta r \mid x, z ; q=1) \neq L(\Delta \mid x ; q=1) & \text { relevance } \\
L\left(\boldsymbol{y}_{j} \mid \boldsymbol{x}, \Delta r, z ; q=1\right)=L\left(\boldsymbol{y}_{j} \mid \boldsymbol{x}, \Delta r ; q=1\right) \text { for } j=0,1 & \text { exogeneity }
\end{array}
$$

where, for example, $L(\Delta r \mid x, z)$ refers to the linear projection of $\Delta r$ on $x$ and $z$.

A few comments are in order. First, we see that Assumption 3 is milder than making assumptions on conditional expectations since identification is based on the usual covariance between instrument and policy intervention. Note also that we explicitly condition only on $q=1$ to emphasize that in our trilemma-based application, these assumptions only need to hold for the subpopulation of pegs. And we remark again that one of the robustness checks that we introduce below will allow for failure of the exclusion restriction in expression (4).

We now have the ingredients required to estimate the causal effects of a policy intervention for the subpopulation of pegs. Using Assumptions 1 and 3, and given a sample of panel data, we can now estimate the following set of local projections using instrumental variables (LP-IV):

$$
y_{i, t+h}=\alpha_{i, h}+x_{i, t} \gamma_{h}+\widehat{\Delta r}_{i, t} \beta_{h}+v_{i, t+h} ; \quad \text { for } h=0, \ldots, H-1,
$$

which can be compared to the LP-OLS form at (2), and where the estimates of $\widehat{\Delta r}_{i, t}$ come from the first stage regression:

$$
\Delta r_{i, t}=a_{i}+x_{i, t} g+z_{i, t} b+\eta_{i, t}
$$

The impulse response can therefore be expressed as:

$$
\mathcal{R}_{L A T E}=E\left(\boldsymbol{y}_{1}-\boldsymbol{y}_{0} \mid \Delta r, \boldsymbol{x}, z ; q=1\right)=\boldsymbol{\beta}=\left(\beta_{0}, \ldots, \beta_{H-1}\right)^{\prime}
$$

which can be estimated from the sequence of equations in expression (5). 
Several remarks are worth making. First, the control vector $x$ will include contemporaneous values of all the variables except the outcome variable (since we begin at $h=0$ to avoid singularity). This is to provide insurance against variation in the policy intervention that could have been explained by information observed concurrently with the policy treatment. Second, expressions (5) and (6) include fixed effects and global GDP to capture global business cycle effects. Third, standard errors are estimated using a clustered-robust covariance matrix estimator. This option allows for a completely unrestricted specification of the covariance matrix of the residuals in the time series dimension by taking advantage of the cross-section. This conveniently takes care of serial correlation in the residuals induced by the local projection setup.

\subsection{Checking for spillovers: robustness of the exclusion restriction}

Economically speaking, a violation of the exclusion restriction could occur if base rates affect home outcomes through channels other than movements in home rates. Additional influences via such channels are sometimes referred to as spillover effects. These could occur if base rates proxy for factors common to all countries. That said, these factors would have to persist despite having included global GDP to soak up such business cycle variation. Our problem, specifically the break down into different subpopulations, offers a unique opportunity to assess such spillover effects more formally than is customarily possible.

Consider a simple example to present the basic idea (Appendix A contains more formal derivations). Let $y$ be a univariate outcome variable, $\Delta r$ the intervention, and $z$ the instrument. We abstract from the constant term, controls, state dependence, and any other complication for now. The standard IV setup consists of the first and second stage regressions given by:

$$
\begin{aligned}
\Delta r & =z b+\eta, \\
y & =\hat{\Delta} r \beta+z \phi+v .
\end{aligned}
$$

Typically we assume $E(\Delta r v) \neq 0$, but $E(z v)=0$. The exclusion restriction refers to the assumption that $\phi=0$. If this restriction were not to hold, it is easy to see that

$$
\hat{\beta}_{I V} \stackrel{p}{\longrightarrow} \beta+\frac{\phi}{b}
$$

This last expression is both simple and intuitive: the bias induced by the failure of the exclusion restriction depends on both the size of the failure, $\phi$, and the strength of the instrument, $b$. Weaker instruments will tend to make the bias worse. This point was made in, for example, Conley, Hansen, and Rossi (2011).

The float subpopulation $(q=0)$ contains useful information that we now exploit. Continue to assume that $E(z v)=0$. We think this is justified since large economies (typically bases) with monetary policy autonomy are unlikely to consider the macroeconomic outlook of smaller countries 
(typically non-base floats) when setting rates. Hence, consider estimating (8) using OLS when $q=0$. Estimates of the intervention effect $\beta$ and the spillover effect $\phi$ will be biased as long as $E(\Delta r v) \neq 0$ and $b \neq 0$. However, it is easy to show (under standard regularity conditions) that the equivalent OLS estimates of expression (8) are such that

$$
\left.\begin{array}{l}
\hat{\beta}_{O L S} \stackrel{p}{\longrightarrow} \beta-\theta \\
\hat{\phi}_{O L S} \stackrel{p}{\longrightarrow} \phi+b \theta
\end{array}\right\} \quad \text { with a bias term } \quad \theta=\frac{E(\Delta r v) E\left(z^{2}\right)}{E(z \Delta r)^{2}-E\left(z^{2}\right) E\left(\Delta r^{2}\right)}
$$

Expression (9) is intuitive. If $E(\Delta r v)>0$, then $\theta>0$ and the effect of domestic interest rates on outcomes, $\hat{\beta}_{\text {OLS }}$, will be attenuated by the bias term $\theta$. Similarly, the spillover effect, $\hat{\phi}_{O L S}$, will be amplified by an amount $b \theta$. This amplification will be larger the stronger the correlation between $\Delta r$ and $z$, as measured by the pseudo first-stage coefficient $b$.

Later we show in Table 5 that the difference between OLS and IV estimates suggests that there is considerable attenuation bias in $\hat{\beta}$. The implication is that simple OLS will tend to make the spillover effect seem larger than it really is, and the interest rate response smaller than it really is. Of course, if $E(\Delta r v)<0$, then $\theta<0$, and the sign of the biases would be reversed. A priori the direction of the bias is ambiguous, as we cautioned earlier.

Without loss of generality, suppose that $\beta=\lambda \phi$, that is, the true domestic interest rate effect on outcomes is a scaled version of the spillover effect from the foreign interest rate. In this case,

$$
\hat{\phi}(\lambda)=\frac{\left(\hat{\phi}_{O L S}+\hat{b} \hat{\beta}_{O L S}\right)}{1+\lambda \hat{b}} \stackrel{p}{\longrightarrow} \beta(\lambda) .
$$

Taking $\lambda$ as given, we can use a control function approach to correct our LP-IV estimates of $\mathcal{R}_{\text {LATE }}$ for biases due to potential spillover effects. Expression (8) can then be rewritten as

$$
(y-z \hat{\phi}(\lambda))=\Delta r \beta+v+z(\hat{\phi}(\lambda)-\phi(\lambda))
$$

Moreover, the usual moment conditions imply that

$$
\begin{aligned}
E(z(y-z \hat{\phi}(\lambda))) & =E(z \Delta r) \beta+E(z v)+E\left(z^{2}(\hat{\phi}(\lambda)-\phi(\lambda))\right) \\
\text { with } E(z v) & =0, \text { and }(\hat{\phi}(\lambda)-\phi(\lambda)) \frac{1}{N_{p}} \sum_{j}^{N_{p}} z_{j}^{2} \stackrel{p}{\longrightarrow} 0
\end{aligned}
$$

as long as

$$
\frac{1}{N_{p}} \sum_{j}^{N_{p}} z_{j}^{2} \stackrel{p}{\longrightarrow} Q_{z}<\infty, \text { and } N_{f} \longrightarrow \infty \text { as } N_{p} \longrightarrow \infty,
$$

with $N_{f}$ and $N_{p}$ denoting the sizes of the subpopulations of floats and pegs respectively.

From this, we can now present a extension of our IV estimator corrected for potential spillover effects, where this new variant is constructed by subtracting the spillover term from the outcome 
variable in the standard IV coefficient estimator, whereby

$$
\hat{\beta}(\lambda) \equiv \frac{\frac{1}{N_{p}} \sum z_{j}\left(y_{j}-z_{j} \hat{\phi}(\lambda)\right)}{\frac{1}{N_{p}} \sum z_{j} \Delta r_{j}} \stackrel{p}{\longrightarrow} \beta(\lambda) .
$$

We assume that the sample sizes of both float and peg subpopulations tend to infinity. In practice, $\lambda$ is unknown. We proceed below by using economic arguments to provide an interval of plausible values $\lambda \in[\underline{\lambda}, \bar{\lambda}]$ over which we compute $\hat{\beta}(\lambda)$. This interval provides a sense of the sensitivity of our benchmark LP-IV estimates of $\mathcal{R}_{\text {LATE }}$ to potential spillover contamination.

\subsection{The roadmap}

The next sections apply the methods just described to investigate the effects of a monetary policy intervention on a wide variety of outcomes central to monetary economics. We begin by assessing identification. A comparison between LP-OLS and LP-IV estimates across subpopulations reveals considerable attenutation bias from poor identification when relying on conditional mean independence. The trilemma instrument greatly improves our estimates. Moreover, to remove any doubts that these results are driven by spillover effects, we conduct robustness analysis. If anything, the main results strengthen.

The next phase of our analysis explores potential state-dependence in our results. The LP-IV framework that we espouse is then particularly well-suited to evaluate whether monetary policy interventions are more or less effective depending on several stratifications of the data. This turns out to be the case, with important implications for how we think about traditional monetary models.

\section{Monetary POlicy interventions: UNDERSTANDING THE SUBPOPULATIONS}

Throughout its history, a country can fall into any of the following bins defined earlier: pegs, floats, and bases. For example, during Bretton Woods, Germany was in a peg to the dollar. With the end of Bretton Woods, and later the introduction of the European Monetary System, we consider Germany to become a base for many European economies. And there are other periods where we classify Germany as a float, as was the case for much of the interwar period. Other than bases, all other countries are either floats or pegs, depending on the period.

When presenting results, we will always measure and display the outcome variable in deviations relative to its initial value in year 0 , with units shown in percent of the initial year value (computed as log change times 100), except in the case of interest rates where the response will be measured in units of percentage points. The policy intervention variable will be defined as the one-year change in the short-term interest rate in year 0 , and normalized in all cases to a 1 percentage point, or 100 basis points (bps) increase. 
The vector of explanatory variables includes a rich set of macroeconomic controls consisting of the first-difference of the contemporaneous values of all variables (excluding the response or outcome variable), and up to 2 lags of the first-difference of all variables, including the response variable. The list of macroeconomic controls is: log real GDP per capita; log real real consumption per capita; log real real investment per capita; log consumer price index; short-term interest rate (usually a 3-month government security); long-term interest rate (usually a 5-year government security); log real house prices; log real stock prices; and the credit to GDP ratio. ${ }^{8}$

In almost all respects, we found that this estimation setup produced stable outcomes. However, in line with the well-known "price puzzle" literature (e.g., Eichenbaum 1992; Sims 1992; Hanson 2004), we found that there was substantial instability in the coefficients of the control variables, and that this finding was driven by the postwar high-inflation period of the 1970s. The traditional resolution of this puzzle has been to include commodity prices as a way to control for oil shocks. Given the constraints of our data, we addressed this issue by allowing the controls to take on a potentially different coefficient for the subsample period of years from 1973 to 1980 inclusive, thus bracketing the volatile period of the two oil crises.

\subsection{LP-OLS: subpopulation $\mathcal{R}_{A T E}$ under conditional mean independence}

We begin our analysis by following the older selection-on-observables tradition. We naïvely estimate via LP-OLS the effect of an interest rate intervention on output (measured by log real GDP per capita) and prices (measured by log CPI) - two variables that commonly feature in many central bank mandates. These results are provided in Table 4 and are based on a panel regression that allows the relevant coefficient estimates to vary for each of the three subpopulations that we consider: pegs, floats and bases.

These estimates are a natural benchmark: if regression control is sufficient to achieve identification, then we could quite easily obtain estimates of $\mathcal{R}_{A T E}$ simply by averaging standard panel-based estimates across subpopulations. Hence the table evaluates whether estimates across subpopulations are statistically different from one another. In addition, we also provide a joint test that, over the 5 horizons considered, the effect of interest rates on output and prices is zero. The analysis is conducted over the full and the post-WW2 samples.

Consider the output responses first, reported in columns 1-3. Full sample results indicate some minor differences across subpopulations. The $p$-values of the null that the coefficients are equal is reported in column 4. The differences are economically minor, however. The post-WW2 results in column 4 suggest that if anything, the differences are even less important over this sample. Generally speaking, the coefficient estimates have the expected signs. An increase in interest rates causes output to decline. Note that in all cases the effect is statistically different from zero as reported in the rows labeled $H_{0}: s u b A T E=0$, by which we denote "subpopulation ATE."

\footnotetext{
${ }^{8}$ The data are described in more detail in Jordà, Schularick, and Taylor (2017), and its online appendix.
} 
Table 4: LP-OLS. Real GDP per capita and CPI price responses to interest rates

Responses at years o to 4 ( $100 \times \log$ change from year o baseline).

\begin{tabular}{|c|c|c|c|c|c|c|c|c|}
\hline \multirow{2}{*}{$\begin{array}{l}\text { (a) Full sample } \\
\text { Year }\end{array}$} & \multicolumn{3}{|c|}{ Output response } & \multirow{2}{*}{$\frac{P=F=B}{p \text {-value }}$} & \multicolumn{3}{|c|}{ Price response } & \multirow{2}{*}{ 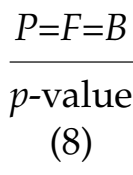 } \\
\hline & $\begin{array}{l}\text { Pegs } \\
\text { (1) }\end{array}$ & $\begin{array}{l}\text { Floats } \\
\text { (2) }\end{array}$ & $\begin{array}{c}\text { Bases } \\
(3)\end{array}$ & & $\begin{array}{c}\text { Pegs } \\
(5)\end{array}$ & $\begin{array}{c}\text { Floats } \\
(6)\end{array}$ & $\begin{array}{c}\text { Bases } \\
(7)\end{array}$ & \\
\hline$h=0$ & $\begin{array}{c}0.09^{* * *} \\
(0.03)\end{array}$ & $\begin{array}{l}-0.11 \\
(0.10)\end{array}$ & $\begin{array}{c}0.22^{* * *} \\
(0.06)\end{array}$ & 0.01 & $\begin{array}{l}0.15^{* *} \\
(0.07)\end{array}$ & $\begin{array}{c}0.35^{* * *} \\
(0.10)\end{array}$ & $\begin{array}{l}-0.05 \\
(0.08)\end{array}$ & 0.01 \\
\hline$h=1$ & $\begin{array}{l}-0.17 \\
(0.11)\end{array}$ & $\begin{array}{c}-0.51^{* * *} \\
(0.15)\end{array}$ & $\begin{array}{c}-0.20^{* *} \\
(0.08)\end{array}$ & 0.14 & $\begin{array}{c}0.17 \\
(0.15)\end{array}$ & $\begin{array}{l}0.57^{* *} \\
(0.24)\end{array}$ & $\begin{array}{l}-0.11 \\
(0.14)\end{array}$ & 0.03 \\
\hline$h=2$ & $\begin{array}{l}-0.25^{*} \\
(0.14)\end{array}$ & $\begin{array}{c}-0.80^{* * *} \\
(0.22)\end{array}$ & $\begin{array}{c}-0.53^{* * *} \\
(0.12)\end{array}$ & 0.06 & $\begin{array}{c}0.15 \\
(0.20)\end{array}$ & $\begin{array}{c}0.40 \\
(0.41)\end{array}$ & $\begin{array}{l}-0.28 \\
(0.18)\end{array}$ & 0.19 \\
\hline$h=3$ & $\begin{array}{c}-0.34^{* *} \\
(0.17)\end{array}$ & $\begin{array}{c}-0.86^{* * *} \\
(0.23)\end{array}$ & $\begin{array}{c}-0.43^{* * *} \\
(0.09)\end{array}$ & 0.17 & $\begin{array}{c}0.07 \\
(0.28)\end{array}$ & $\begin{array}{c}0.07 \\
(0.54)\end{array}$ & $\begin{array}{c}-0.58^{* *} \\
(0.23)\end{array}$ & 0.22 \\
\hline$h=4$ & $\begin{array}{l}-0.33 \\
(0.20)\end{array}$ & $\begin{array}{c}-0.84^{* * *} \\
(0.31)\end{array}$ & $\begin{array}{c}-0.34^{* *} \\
(0.13)\end{array}$ & 0.20 & $\begin{array}{c}0.00 \\
(0.39)\end{array}$ & $\begin{array}{l}-0.06 \\
(0.64)\end{array}$ & $\begin{array}{c}-0.85^{* *} \\
(0.33)\end{array}$ & 0.22 \\
\hline$H_{0}: s u b A T E=0$ & 0.00 & 0.01 & 0.01 & & 0.26 & 0.01 & 0.93 & \\
\hline Observations & & 1253 & & & & 1285 & & \\
\hline (b) Post-WW2 & (1) & (2) & (3) & (4) & (5) & (6) & (7) & (8) \\
\hline$h=0$ & $\begin{array}{l}0.04^{*} \\
(0.02)\end{array}$ & $\begin{array}{l}-0.01 \\
(0.08)\end{array}$ & $\begin{array}{l}0.13^{* *} \\
(0.05)\end{array}$ & 0.23 & $\begin{array}{l}0.14^{* *} \\
(0.06)\end{array}$ & $\begin{array}{l}0.16^{* *} \\
(0.07)\end{array}$ & $\begin{array}{l}0.03 \\
(0.06)\end{array}$ & 0.19 \\
\hline$h=1$ & $\begin{array}{l}-0.18 \\
(0.11)\end{array}$ & $\begin{array}{c}-0.31^{* *} \\
(0.15)\end{array}$ & $\begin{array}{c}-0.29^{* * *} \\
(0.10)\end{array}$ & 0.62 & $\begin{array}{l}0.22^{*} \\
(0.11)\end{array}$ & $\begin{array}{l}0.36^{* *} \\
(0.18)\end{array}$ & $\begin{array}{c}0.11 \\
(0.12)\end{array}$ & 0.30 \\
\hline$h=2$ & $\begin{array}{c}-0.29^{* *} \\
(0.15)\end{array}$ & $\begin{array}{c}-0.55^{* * *} \\
(0.20)\end{array}$ & $\begin{array}{c}-0.66^{* * *} \\
(0.13)\end{array}$ & 0.08 & $\begin{array}{c}0.13 \\
(0.17)\end{array}$ & $\begin{array}{c}0.23 \\
(0.30)\end{array}$ & $\begin{array}{l}-0.04 \\
(0.15)\end{array}$ & 0.59 \\
\hline$h=3$ & $\begin{array}{c}-0.37^{* *} \\
(0.16)\end{array}$ & $\begin{array}{c}-0.52^{* * *} \\
(0.19)\end{array}$ & $\begin{array}{c}-0.66^{* * *} \\
(0.10)\end{array}$ & 0.17 & $\begin{array}{l}-0.09 \\
(0.24)\end{array}$ & $\begin{array}{l}-0.18 \\
(0.40)\end{array}$ & $\begin{array}{c}-0.41^{* *} \\
(0.19)\end{array}$ & 0.55 \\
\hline$h=4$ & $\begin{array}{c}-0.35^{*} \\
\text { (o.19) }\end{array}$ & $\begin{array}{c}-0.52^{* *} \\
(0.24)\end{array}$ & $\begin{array}{c}-0.72^{* * *} \\
(0.12)\end{array}$ & 0.21 & $\begin{array}{l}-0.23 \\
(0.32)\end{array}$ & $\begin{array}{l}-0.40 \\
(0.49)\end{array}$ & $\begin{array}{c}-0.69^{* * *} \\
(0.26)\end{array}$ & 0.45 \\
\hline$H_{0}: s u b A T E=0$ & 0.00 & 0.01 & 0.00 & & 0.00 & 0.00 & 0.16 & \\
\hline Observations & & 897 & & & & 929 & & \\
\hline
\end{tabular}

Notes: ${ }^{* * *} p<0.01,{ }^{* *} p<0.05,{ }^{*} p<0.1$. $P$ denotes pegs, $F$ floats, $B$ bases. Cluster robust standard errors in parentheses. Full sample: 1870-2013 excluding WW1: 1914-1919 and WW2: 1939-1947. PostWW2 sample: 1948-2013. The column $P=F=B$ displays the $p$-value of the null that for a given horizon $h$, estimates of the corresponding elasticity are equal across subpopulations. $H_{0}: s u b A T E=0$ refers to the null that the coefficients for $h=0, \ldots, 4$ are jointly zero for a given subpopulation. See text. 
The price responses reported in columns 5-7 fit intuition less neatly. The overall effect of an interest rate increase on prices in the full sample is essentially null for pegs and floats (columns 5 and 6 respectively), but negative for bases with a -0.85 significant response in year $h=4$. The picture changes somewhat for the post-WW2 subsample. Responses are essentially zero for $h=0,1$, and 2. Negative signs appear for $h=3$, and 4, but the responses are generally not very different from zero in the statistical sense (except for bases, again).

What are the main takeaways from the naïve LP-OLS estimates Table 4 ? On first glance there is little evidence that anything is amiss. Output and price responses across subpopulations are similar, have the expected signs, and are statistically significant (although for prices only after year $h=3$ ). On average across subpopulations, post-WW2 results indicate that a one percent increase in interest rates would reduced output and price levels about 0.5 percentage points over 5 years, roughly a 0.1 percent in annual rate of decline. The price responses offer a less reassuring picture, in large part because the responses are generally insignificant and often have the "wrong" sign early on. The next step is to examine the estimates of the local average treatment effect for the pegs and for bases. Here, any departure from the parameter estimates just reported above would be indicative of a violation of the conditional mean independence assumption.

\subsection{LP-IV $\mathcal{R}_{L A T E}$ : two instruments, two subpopulations}

We now compare LP-OLS estimates with LP-IV estimates based on our trilemma instrument for the subpopulation of pegs by matching the samples. This will generate small differences between the LP-OLS estimates in Table 5 and those in columns 1 and 5 in Table 4 . We calculate the $\mathcal{R}_{\text {LATE }}$ of an interest rate intervention and evaluate any attenuation bias from violations of conditional mean independence using a Hausman test. Table 5 summarizes the main results.

The table is organized as follows. The output and price responses in columns 1 and 4 are LP-OLS estimates over the same sample as the LP-IV estimates reported in columns 2 and 5. Column 3 reports the $p$-value of the Hausman test of the null that the estimate in column 1 is equal to that in column 2; likewise, column 6 reports the Hausman test for columns 4 and 5. We check (again) whether the trilemma instrument is weak with Kleibergen-Paap tests. Finally, we test the null that all ATE coefficients are jointly zero, reporting the $p$-value of the test in the row labeled $H_{0}: s u b A T E=0$.

The first task is to compare the LP-OLS responses reported in columns 1 and 4 here, with those reported in Table 4 in columns 1 and 5 . Recall that in Table 4 we estimate the model using all observations, but allow coefficients to vary by subpopulation. The differences are relatively minor, owing to slight differences in the sample used given the availability of the instrument.

The important result of Table 5 is the size of the attenuation bias in the case of LP-OLS compared to LP-IV. The differences are economically sizable and statistically significant as indicated by the Hausman tests of columns 3 and 6. Conditional mean independence clearly fails. Using LP-OLS estimates (column 1) and the full sample, output would be estimated to be about $0.18 \%$ lower four 
Table 5: LP-OLS vs. LP-IV. Attenuation bias of real GDP per capita and CPI price responses to interest rates. Trilemma instrument. Matched samples

Responses at years o to $4(100 \times \log$ change from year o baseline).

\begin{tabular}{|c|c|c|c|c|c|c|}
\hline \multirow{2}{*}{$\begin{array}{l}\text { (a) Full sample } \\
\text { Year }\end{array}$} & \multicolumn{2}{|c|}{ Output response } & \multirow{2}{*}{ 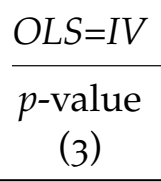 } & \multicolumn{2}{|c|}{ Price response } & \multirow{2}{*}{ 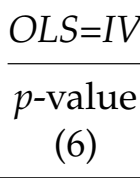 } \\
\hline & $\begin{array}{l}\text { LP-OLS } \\
(1)\end{array}$ & $\begin{array}{l}\text { LP-IV } \\
(2)\end{array}$ & & $\begin{array}{c}\text { LP-OLS } \\
(4)\end{array}$ & $\begin{array}{l}\text { LP-IV } \\
(5)\end{array}$ & \\
\hline$h=0$ & $\begin{array}{l}0.11^{* * *} \\
(0.03)\end{array}$ & $\begin{array}{l}-0.21^{*} \\
(0.11)\end{array}$ & 0.01 & $\begin{array}{l}0.10^{*} \\
(0.05)\end{array}$ & $\begin{array}{l}-0.21 \\
(0.19)\end{array}$ & 0.11 \\
\hline$h=1$ & $\begin{array}{l}-0.18^{*} \\
(0.10)\end{array}$ & $\begin{array}{c}-0.99^{* * *} \\
(0.23)\end{array}$ & 0.00 & $\begin{array}{c}0.17 \\
(0.11)\end{array}$ & $\begin{array}{c}-0.68^{* *} \\
(0.33)\end{array}$ & 0.01 \\
\hline$h=2$ & $\begin{array}{l}-0.22 \\
(0.16)\end{array}$ & $\begin{array}{c}-1.88^{* * *} \\
(0.33)\end{array}$ & 0.00 & $\begin{array}{c}0.02 \\
(0.18)\end{array}$ & $\begin{array}{c}-1.57^{* * *} \\
(0.43)\end{array}$ & 0.00 \\
\hline$h=3$ & $\begin{array}{l}-0.26 \\
(0.21)\end{array}$ & $\begin{array}{c}-2.20^{* * *} \\
(0.42)\end{array}$ & 0.00 & $\begin{array}{l}-0.22 \\
(0.30)\end{array}$ & $\begin{array}{c}-2.84^{* * *} \\
(0.70)\end{array}$ & 0.00 \\
\hline$h=4$ & $\begin{array}{l}-0.18 \\
(0.25)\end{array}$ & $\begin{array}{c}-2.87^{* * *} \\
(0.54)\end{array}$ & 0.00 & $\begin{array}{l}-0.39 \\
(0.43)\end{array}$ & $\begin{array}{c}-3.83^{* * *} \\
(0.92)\end{array}$ & 0.00 \\
\hline KP weak IV & & 87.83 & & & 70.57 & \\
\hline$H_{0}: s u b A T E=0$ & 0.00 & 0.00 & & 0.01 & 0.00 & \\
\hline Observations & 667 & 667 & & 667 & 667 & \\
\hline (b) Post-WW2 & (1) & $(2)$ & (3) & (4) & (5) & (6) \\
\hline$h=0$ & $\begin{array}{c}0.06^{* * *} \\
(0.02)\end{array}$ & $\begin{array}{l}-0.02 \\
(0.07)\end{array}$ & 0.24 & $\begin{array}{c}0.05 \\
(0.05)\end{array}$ & $\begin{array}{c}0.17 \\
(0.14)\end{array}$ & 0.39 \\
\hline$h=1$ & $\begin{array}{l}-0.13 \\
(0.09)\end{array}$ & $\begin{array}{c}-0.75^{* * *} \\
(0.25)\end{array}$ & 0.01 & $\begin{array}{c}0.11 \\
(0.08)\end{array}$ & $\begin{array}{c}0.08 \\
(0.26)\end{array}$ & 0.89 \\
\hline$h=2$ & $\begin{array}{l}-0.22^{*} \\
(0.13)\end{array}$ & $\begin{array}{c}-1.58^{* * *} \\
(0.35)\end{array}$ & 0.00 & $\begin{array}{l}-0.03 \\
(0.13)\end{array}$ & $\begin{array}{l}-0.46 \\
(0.32)\end{array}$ & 0.18 \\
\hline$h=3$ & $\begin{array}{l}-0.24 \\
(0.16)\end{array}$ & $\begin{array}{c}-1.70^{* * *} \\
(0.37)\end{array}$ & 0.00 & $\begin{array}{l}-0.27 \\
(0.22)\end{array}$ & $\begin{array}{c}-1.21^{* * *} \\
(0.42)\end{array}$ & 0.03 \\
\hline$h=4$ & $\begin{array}{l}-0.17 \\
(0.20)\end{array}$ & $\begin{array}{c}-2.20^{* * *} \\
(0.50)\end{array}$ & 0.00 & $\begin{array}{l}-0.47 \\
(0.34)\end{array}$ & $\begin{array}{c}-1.78^{* * *} \\
(0.54)\end{array}$ & 0.02 \\
\hline KP weak IV & & 91.04 & & & 77.14 & \\
\hline$H_{0}: s u b A T E=0$ & 0.00 & 0.00 & & 0.01 & 0.01 & \\
\hline Observations & 522 & 522 & & 522 & 522 & \\
\hline
\end{tabular}

Notes: ${ }^{* * *} p<0.01,{ }^{* *} p<0.05,{ }^{*} p<0.1$. Cluster robust standard errors in parentheses. Full sample: $1870-2013$ excluding WW1: 1914-1919 and WW2: 1939-1947. PostWW2 sample: 1948-2013. Matched sample indicates LP-OLS sample matches the sample used to obtain LP-IV estimates. KP weak IV refers to the Kleibergen-Paap test for weak instruments. $H_{0}: s u b A T E=0$ refers to the $p$-value of the test of the null hypothesis that the coefficients for $h=0, \ldots, 4$ are jointly zero for a given subpopulation. OLS=IV shows the $p$-value for the Hausman test of the null that OLS estimates equal IV estimates. See text. 
years after an increase in interest rates of $1 \%$. In contrast, the LP-IV effect is measured to be nearly a $2.9 \%$ decline, or about a $0.5 \%$ annualized rate of lower growth. A similar pattern is observable for the price response. Full sample LP-OLS estimates are largely insignificant and often have the wrong sign. LP-IV estimates are sizable, significant, and have the right sign.

Comparing the full sample results with the post-WW2 results we find differences in the output response to be relatively minor. The price response, however, becomes somewhat delayed or stickier after WW2. The LP-IV response suggests that on impact and the year after, the price response is essentially zero although by year 4 , prices are expected to be about $1.8 \%$ lower than they were four years earlier. Tests for weak instruments suggest the trilemma instrument is relevant and tests of the null show that the $\mathcal{R}_{L A T E}$ estimated with LP-IV is statistically different from zero. Interest rates do indeed have a strong causal effect on output and prices for the subpopulation of pegs.

Next, Table 6 compares these results with estimates based on a different instrumental variable and subpopulation. We turn to the Romer and Romer (2004) instrument for the U.S., as updated and extended to the U.K. by Cloyne and Hürtgen (2016). We shall henceforth refer to this instrument as $R R C H$. Both the U.S. and the U.K. can be thought of as belonging to the subpopulation of bases and thus provide the best approximation of the $\mathcal{R}_{L A T E}$ results for this group, where we should note that a similar IV for Germany as a base is not (yet) available.

The results in Table 6 are organized in a manner similar to Table 5. The table reports the output and price responses estimated by LP-OLS and LP-IV using the RRCH instrument. We note that the RRCH instrument is available only from 1969 to 2007 for the U.S. and 1976 to 2007 for the U.K. Because of the abbreviated sample, we limit the control set to save on degrees of freedom. We allow up to 3 lags of interest rates, output and inflation, but omit all other controls. This parsimonious specification still allows coefficients to vary over the oil crisis period of 1973-1980, as before. In terms of a formal model, one can think of this specification as the empirical counterpart to a three-variable New Keynesian VAR specification.

We can see that the LP-OLS and LP-IV estimates of the output response appear similar from the statistical perspective of the Hausman test reported in column 3. However, the sample is rather limited. Only 71 observations taxed by 11 regressors (a different constant for U.S. and U.K. observations and nine regressors). Economically speaking, there is a fair amount of attenuation bias. By year $h=4$ the LP-OLS response is -0.37 compared to -1.88 for LP-IV. That said, both methods generally deliver the correct sign and the responses have a similar shape. The differences are more apparent for the price response. The LP-OLS response of prices to an interest rate intervention (column 4) is economically and statistically small, with coefficients that have the wrong sign (except for the last). The LP-IV response has a similarly muted response initially but it becomes increasingly negative. By year 4, prices are expected to be about 3.1\% lower than they would otherwise would be, a response for bases that is similar to that for pegs based on the trilemma IV as reported previously in Table 5 . 
Table 6: LP-OLS vs. LP-IV. Attenuation bias of real GDP per capita and CPI price responses to interest rates. U.S. and U.K. using RRCH instrument.

Responses at years o to 4 ( $100 \times \log$ change from year o baseline).

\begin{tabular}{|c|c|c|c|c|c|c|}
\hline \multirow{2}{*}{$\begin{array}{l}\text { RRCH IV } \\
\text { Year }\end{array}$} & \multicolumn{2}{|c|}{ Output response } & \multirow{2}{*}{$\frac{O L S=I V}{p \text {-value }}$} & \multicolumn{2}{|c|}{ Price response } & \multirow{2}{*}{$\begin{array}{c}O L S=I V \\
p \text {-value } \\
(6)\end{array}$} \\
\hline & $\begin{array}{l}\text { LP-OLS } \\
\quad(1)\end{array}$ & $\begin{array}{l}\text { LP-IV } \\
(2)\end{array}$ & & $\begin{array}{l}\text { LP-OLS } \\
(4)\end{array}$ & $\begin{array}{l}\text { LP-IV } \\
\text { (5) }\end{array}$ & \\
\hline$h=0$ & $\begin{array}{l}0.35^{* * *} \\
(0.10)\end{array}$ & $\begin{array}{c}0.05 \\
(0.40)\end{array}$ & 0.74 & $\begin{array}{l}0.19^{* *} \\
(0.08)\end{array}$ & $\begin{array}{l}-0.17 \\
(0.31)\end{array}$ & 0.15 \\
\hline$h=1$ & $\begin{array}{l}-0.04 \\
(0.20)\end{array}$ & $\begin{array}{l}-0.59 \\
(0.74)\end{array}$ & 0.41 & $\begin{array}{c}0.58^{* * *} \\
(0.19)\end{array}$ & $\begin{array}{c}0.32 \\
(0.47)\end{array}$ & 0.61 \\
\hline$h=2$ & $\begin{array}{l}-0.54 \\
(0.34)\end{array}$ & $\begin{array}{l}-1.71 \\
(1.20)\end{array}$ & 0.19 & $\begin{array}{l}0.63^{* *} \\
(0.30)\end{array}$ & $\begin{array}{c}0.24 \\
(0.80)\end{array}$ & 0.66 \\
\hline$h=3$ & $\begin{array}{l}-0.50 \\
(0.45)\end{array}$ & $\begin{array}{l}-2.19 \\
(1.44)\end{array}$ & 0.18 & $\begin{array}{c}0.34 \\
(0.38)\end{array}$ & $\begin{array}{l}-1.00 \\
(1.44)\end{array}$ & 0.31 \\
\hline$h=4$ & $\begin{array}{l}-0.37 \\
(0.46)\end{array}$ & $\begin{array}{l}-1.88 \\
(1.41)\end{array}$ & 0.23 & $\begin{array}{l}-0.03 \\
(0.47)\end{array}$ & $\begin{array}{l}-3.05 \\
(2.42)\end{array}$ & 0.16 \\
\hline $\begin{array}{l}\text { KP weak IV } \\
H_{0}: s u b A T E=0\end{array}$ & 0.00 & $\begin{array}{l}4.25 \\
0.35\end{array}$ & & 0.00 & $\begin{array}{l}5 \cdot 73 \\
0.06\end{array}$ & \\
\hline Observations & 71 & 71 & & 71 & 71 & \\
\hline
\end{tabular}

Notes: ${ }^{* * *} p<0.01,{ }^{* *} p<0.05, * p<0.1$. Cluster robust standard errors in parentheses. RRCH refers to the Romer and Romer (2004) and Cloyne and Hürtgen (2016) IV. U.S. sample: 1969-2007. U.K. sample: 1976-2007. $K P$ weak $I V$ refers to the Kleibergen-Paap test for weak instruments. $H_{0}: s u b A T E=0$ refers to the $p$-value of the test of the null hypothesis that the coefficients for $h=0, \ldots, 4$ are jointly zero for a given subpopulation. $O L S=I V$ shows the $p$-value for the Hausman test of the null that OLS estimates equal IV estimates. See text.

\subsection{Checking for spillovers}

Table 7 reports OLS estimates of expression (8), based on the float subpopulation (and by including the usual control set). We employ the same trilemma instrument, defined exactly as before, but now utilize it in the float subpopulation to operationalize our control function approach. The left-hand side variables are log real GDP per capita and log CPI price level. Table 7 also reports the coefficient associated with the pseudo-first stage regression of $\Delta r$ on $z$. This provides an estimate of the parameter $b$ in expression (9).

Table 7 makes clear the intuition behind expression (9). The interest rate responses of real GDP per capita reported in column 1 are economically small. They are statistically insignificant for the full sample estimates reported in panel (a) of the table, and only significant in years 3 and 4 in the Post-WW2 sample reported in panel (b). In contrast, the response to the instrument (think of it as a shock to the base country interest rate) is almost three times larger and significant. Price responses follow a different pattern, with responses to the own interest rate shock of the wrong sign, but responses to the base country interest rate (measured by the instrument) of the correct sign. This is 
Table 7: LP-OLS. Real GDP per capita and CPI price responses to domestic and base-country interest rates. Full and post-WW2 samples for subpopulation of exchange rate float economies

Responses at years o to 4 ( $100 \times \log$ change from year o baseline).

\begin{tabular}{|c|c|c|c|c|c|c|}
\hline \multirow[t]{2}{*}{ (a) Full sample } & \multicolumn{2}{|c|}{ Output response to } & \multirow{2}{*}{$\begin{array}{c}\Delta r=z \\
p \text {-value } \\
\text { (3) }\end{array}$} & \multicolumn{2}{|c|}{ Price response to } & \multirow{2}{*}{$\begin{array}{c}\Delta r=z \\
p \text {-value } \\
\text { (6) }\end{array}$} \\
\hline & $\begin{array}{l}\Delta r \\
(1)\end{array}$ & $\begin{array}{c}z \\
(2)\end{array}$ & & $\begin{array}{l}\Delta r \\
(4)\end{array}$ & $\begin{array}{c}z \\
(5)\end{array}$ & \\
\hline$h=0$ & $\begin{array}{l}-0.05 \\
(0.15)\end{array}$ & $\begin{array}{c}0.09 \\
(0.09)\end{array}$ & 0.43 & $\begin{array}{l}0.53^{* *} \\
(0.22)\end{array}$ & $\begin{array}{l}-0.15 \\
(0.24)\end{array}$ & 0.09 \\
\hline$h=1$ & $\begin{array}{l}-0.24 \\
(0.26)\end{array}$ & $\begin{array}{l}-0.13 \\
(0.22)\end{array}$ & 0.80 & $\begin{array}{l}1.17^{* *} \\
(0.49)\end{array}$ & $\begin{array}{l}-0.30 \\
(0.50)\end{array}$ & 0.11 \\
\hline$h=2$ & $\begin{array}{l}-0.23 \\
(0.31)\end{array}$ & $\begin{array}{l}-0.57^{* *} \\
(0.22)\end{array}$ & 0.48 & $\begin{array}{l}1.45^{* *} \\
(0.66)\end{array}$ & $\begin{array}{l}-0.62 \\
(0.71)\end{array}$ & 0.10 \\
\hline$h=3$ & $\begin{array}{l}-0.21 \\
(0.29)\end{array}$ & $\begin{array}{c}-1.08^{* * *} \\
(0.32)\end{array}$ & 0.10 & $\begin{array}{c}1.35 \\
\text { (o.8o) }\end{array}$ & $\begin{array}{l}-1.13 \\
(0.88)\end{array}$ & 0.10 \\
\hline$h=4$ & $\begin{array}{l}-0.06 \\
(0.30)\end{array}$ & $\begin{array}{c}-1.40^{* * *} \\
(0.45)\end{array}$ & 0.04 & $\begin{array}{l}1.48 \\
(0.89)\end{array}$ & $\begin{array}{l}-1.70 \\
(1.00)\end{array}$ & 0.06 \\
\hline $\begin{array}{l}\Delta r \text { on } z \\
\quad \text { first stage estimate }\end{array}$ & & & & & & \\
\hline Observations & & & & & & \\
\hline (b) Post-WW2 & (1) & (2) & (3) & (4) & (5) & (6) \\
\hline$h=0$ & $\begin{array}{l}-0.06 \\
(0.10)\end{array}$ & $\begin{array}{l}-0.03 \\
(0.11)\end{array}$ & 0.78 & $\begin{array}{c}0.37 \\
(0.22)\end{array}$ & $\begin{array}{l}-0.36^{*} \\
(0.19)\end{array}$ & 0.05 \\
\hline$h=1$ & $\begin{array}{l}-0.22 \\
(0.16)\end{array}$ & $\begin{array}{l}-0.28 \\
(0.26)\end{array}$ & 0.86 & $\begin{array}{c}0.58 \\
(0.44)\end{array}$ & $\begin{array}{l}-0.64 \\
(0.43)\end{array}$ & 0.10 \\
\hline$h=2$ & $\begin{array}{l}-0.21 \\
(0.26)\end{array}$ & $\begin{array}{c}-0.84^{* *} \\
(0.36)\end{array}$ & 0.29 & $\begin{array}{c}0.82 \\
(0.62)\end{array}$ & $\begin{array}{l}-0.86 \\
(0.62)\end{array}$ & 0.13 \\
\hline$h=3$ & $\begin{array}{l}-0.34^{*} \\
(0.18)\end{array}$ & $\begin{array}{c}-1.51^{* * *} \\
(0.33)\end{array}$ & 0.01 & $\begin{array}{c}0.78 \\
(0.71)\end{array}$ & $\begin{array}{l}-1.31 \\
(0.78)\end{array}$ & 0.13 \\
\hline$h=4$ & $\begin{array}{l}-0.41^{* *} \\
(0.18)\end{array}$ & $\begin{array}{c}-1.90^{* * *} \\
(0.46)\end{array}$ & 0.00 & $\begin{array}{c}0.99 \\
(0.78)\end{array}$ & $\begin{array}{l}-1.87^{*} \\
(0.94)\end{array}$ & 0.07 \\
\hline $\begin{array}{l}\Delta r \text { on } z \\
\quad \text { first stage estimate }\end{array}$ & & & & & & \\
\hline Observations & & & & & & \\
\hline
\end{tabular}

Notes: ${ }^{* * *} p<0.01,{ }^{* *} p<0.05,{ }^{*} p<0.1$. Cluster robust standard errors in parentheses. $\Delta r$ is the short-term interest rate of the domestic economy considered and indexed by $i ; z_{i, t}$ refers to the base country short-term interest rate times the openness index. We use the U.K. as the base before 1939; we use the U.S. for the BrettonWoods era (1946-1971) for all countries, and for Australia, Canada, Japan, and the U.K. after Bretton-Woods (1972 onward); and we use Germany for all remaining economies (all in Europe) in the post Bretton-Woods era (1972 onward). $\Delta r=z$ refers to the test of the null that the coefficient for the float rate is equal to that for the instrument and report the p-value of the test. $\Delta r$ on $z$ refers to the coefficient of the regression of the float rate on the instrument (called $b$ in expression (8)). See text. 
a feature we will return to in the results reported below.

Finally, we note that the regression of the domestic interest rate on the instrument and the control set is generally non-zero, but about half to one third the magnitude of the coefficient estimated in the first stage regression for the peg subpopulation and reported in Table 3. Compare 0.20 for the floats with 0.40 for the pegs (using full sample estimates in the case for output). These results are consistent with those reported in Obstfeld, Shambaugh, and Taylor (2005).

Lastly, to make any progress we need auxiliary assumptions on $\lambda$, which cannot be determined from the data. We assert that it is natural to assume that $\lambda \geq 1$. That is, we assume that home rates affect outcomes at least as strongly as rates in the foreign base country. In order to provide bounds, we use a range of values of $\lambda$ between 1 and 4 . In other words, the home rate effect is assumed to be 1 to 4 times larger than the base rate effect.

Using these assumptions and our spillover correction, Figure 1 shows our adjusted estimates of $\mathcal{R}_{\text {LATE}}$, for a 100 bps impulse, as before. The figure displays responses to a $1 \%$ increase in home rates for real GDP per capita and the price level using alternative estimators. The red dashed lines show the responses reported in Table 5, columns 1 and 4, based on LP-OLS and the rich control set described above. As we noted, the responses for GDP generally have the correct sign but are economically and statistically small. This is in line with the attenuation bias described in expression (9). Next, the solid blue lines with associated point-wise error bands in grey show the LP-IV estimates reported in Table 5, columns 2 and 5. As we noted, the responses are considerably larger, both statistically (the null $H_{0}: s u b A T E=0$ is rejected at the $1 \%$ level) and economically. Finally, the light green shaded region with a dashed border displays the range of responses that would result from our spillover correction using $\lambda \in[1,4]$.

Several results deserve comment. First, the correction for spillover effects tends to attenuate the output responses as compared to our preferred LP-IV estimates. The correction suggests that the output response is about 0.5 to 1 percentage points less negative by year 4 than that reported using LP-IV alone. In the post-WW2 era this means that the cumulative change in output is probably closer to $-1.5 \%$ (about $-0.3 \%$ per annum) than to $-2.5 \%$ (about $-0.5 \%$ per annum). Interestingly, the response of prices is amplified. The reason is easy to see in Table 7. The LP-OLS estimate of the effect of domestic interest rates on prices is positive rather than negative. Meanwhile, the effect of base country interest rates is strongly negative. Thus, the correction makes the LP-IV price response more sensitive to interest rates, especially on impact. This feature has often been an achilles heel of the post-WW2 U.S. VAR literature, where findings often have a price response with the wrong sign or a price response that remains largely muted for a prolonged period of time even as the response of output shows a more immediate response. These results are reassuring. Our LP-IV estimates are reasonably robust to potential spillover effects under economically meaningful scenarios. Even if the spillover effects were large, the true estimate would be still be much closer to the LP-IV estimates that we report than to the LP-OLS estimates commonly found in the literature. 
Figure 1: Real GDP per capital and CPI price responses to a 1 percent increase in interest rates. LP-OLS, $L P-I V$, and spillover corrected LP-IV

(a) Full sample

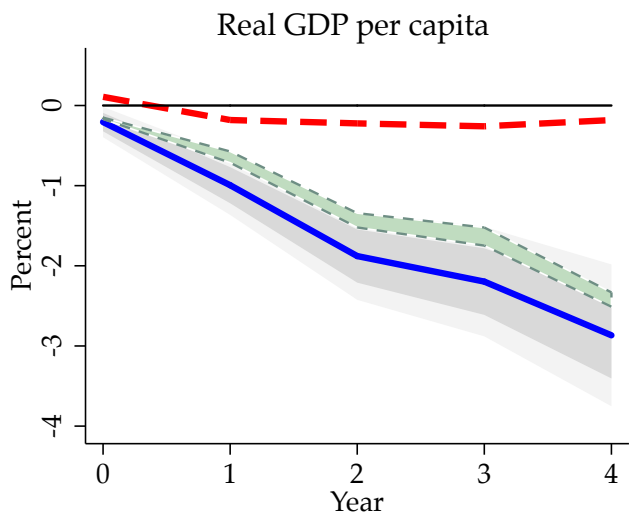

Price level

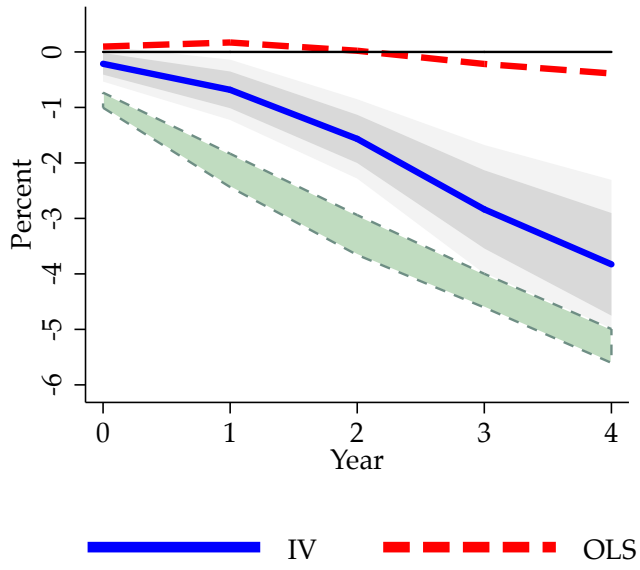

(b) Post-WW2

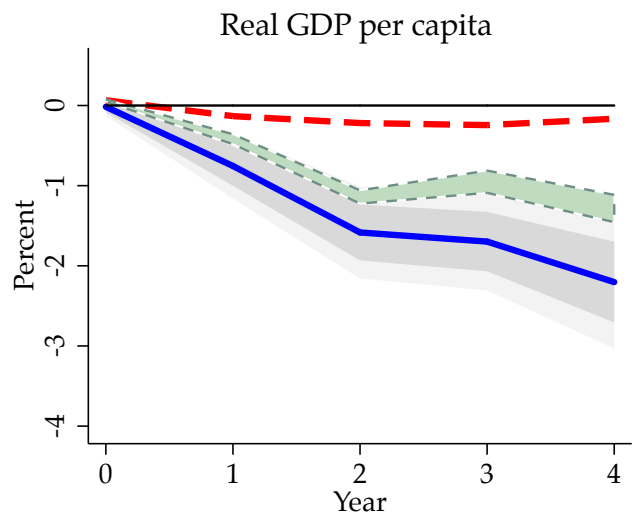

Price level

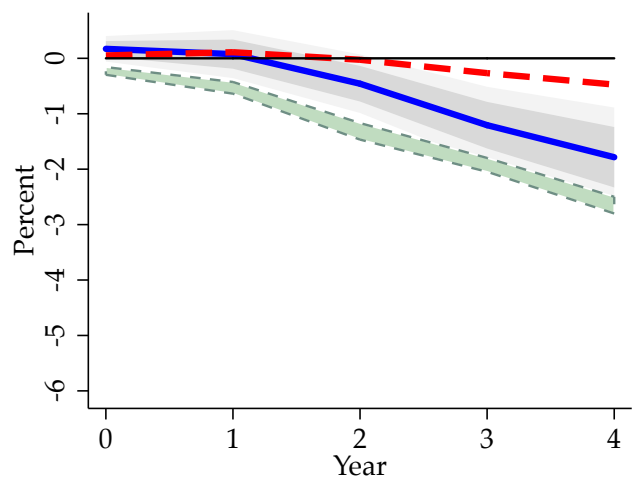

IV spillover corrected

Notes: Full sample: 1870-2013 excluding WW1: 1914-1919 and WW2: 1939-1947. LP-OLS estimates displayed as a dashed red line, LP-IV estimates displayed as a solid blue line and I S.D. and 90\% confidence bands, LP-IV spillover corrected estimates displayed as a light green shaded area with dashed border, using $\lambda \in[1,4]$. See text.

\section{The CAUSAl EFFECTS OF INTEREST RATES ON THE MACROECONOMY}

In this section we briefly present a comprehensive study of the causal response of a wider array of macroeconomic outcomes to a short-term interest rate increase of $+100 \mathrm{bps}$. Figure 2 summarizes the responses of our full set of variables for the full sample (the equivalent figure using the Post-WW2 sample only is virtually identical and provided in Appendix B for completeness as Figure B.1).

Starting at the top left chart of Figure 2, we see that a +100 bps increase in the short rate causally leads to a $2 \%$ decline in real GDP per capita (or about $-0.5 \%$ per annum), a $1.5 \%$ decline in real consumption per capita, a 3.5\% decline in real investment per capita, and a 3\% decline in the 
Figure 2: Full baseline results. Full sample
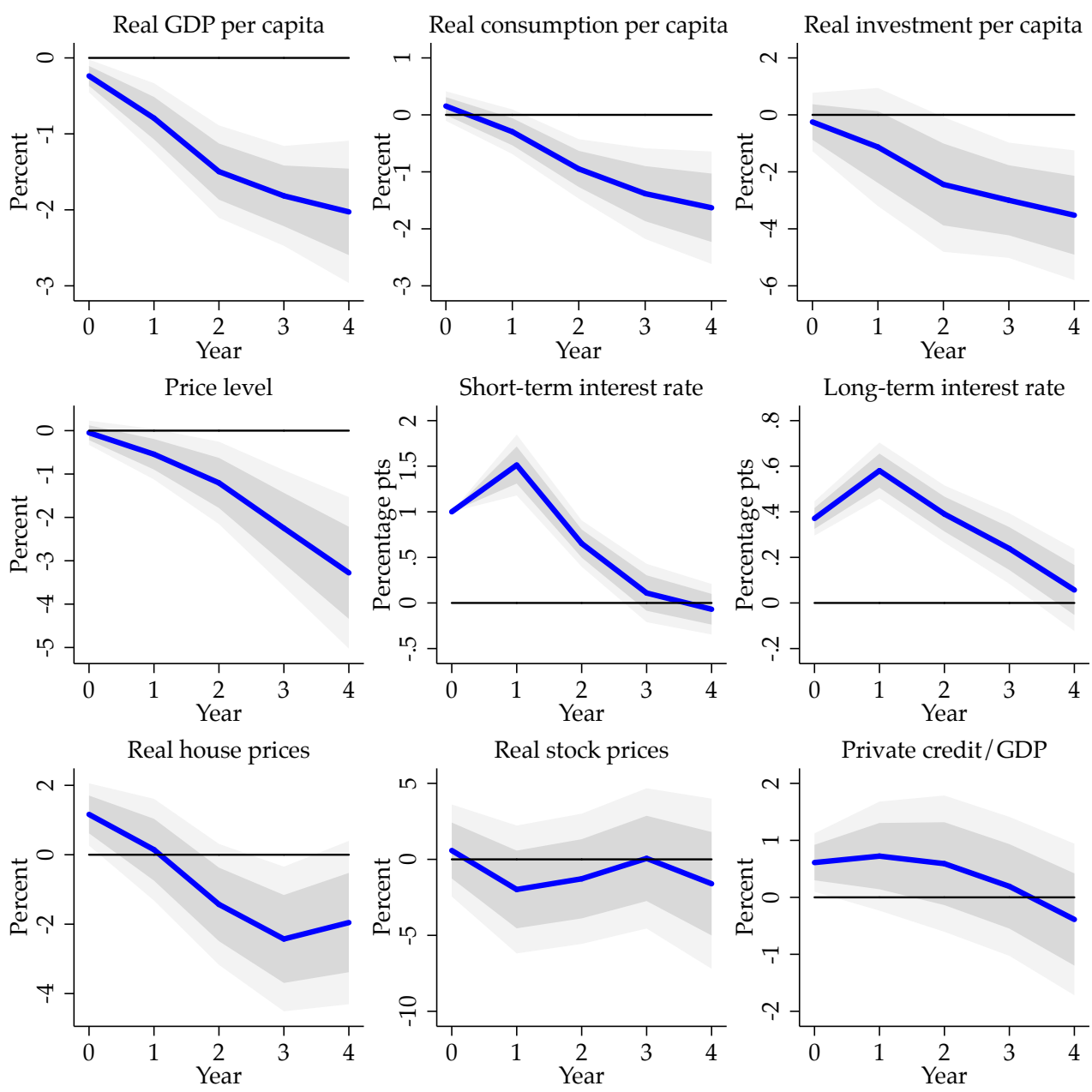

Notes: Full sample: 1870-2013 excluding WW1: 1914-1919 and WW2: 1939-1947. LP-IV estimates displayed with a solid blue line and I S.D. and 90\% confidence bands. See text.

price level (in the second row, first column), where all effects are relative to the no-change policy counterfactual and the measurements are cumulative over the horizon of 4 years.

Moving along the second row of charts in Figure 2, we look first at the own response of shortterm interest rates to $\mathrm{a}+100 \mathrm{bps}$ rate rise in year o (row 2, column 2). This path reflects the intrinsic persistence of changes in interest rates. In this case, short-term interest rates increase by $+150 \mathrm{bps}$ in year 1, drop back to +75 bps in year 2, and then decline to effectively zero in both years 3 and 4 . The next chart (row 2, column 3) shows the response of long-term interest rates, which are, as is well-known, more subdued in amplitude than short rates; the long-term interest rate moves about half as much. A +100 bps rise in the short rate causally leads to the long rate rising +40 bps in year 1 , rising to +60 bps in year 2 , and then falling back towards zero by year 4 .

Proceeding to the last row of charts in Figure 2 (columns 1 and 2), we can examine the responses 
of two key asset prices: $a+100$ bps rise in the short rate causally leads to a cumulative $2 \%$ decline in real house prices and a cumulative $1.5 \%$ decline in real stock prices over 4 years, again as compared to the no-change policy counterfactual. Although these real responses may appear quite small, bear in mind that the nominal responses are far larger in the negative direction, as reported in Figure B.2 in Appendix B. That is, nominal asset prices drop strongly and quickly in response to an interest rate hike. Overall, these asset price responses are consistent with a significant wealth-effect channel for monetary policy, working alongside the more often noted income-effect channel visible in the path of real GDP.

Finally, in the last row and column of Figure 2, we display the causal response of aggregate credit (bank lending to the nonfinancial sector relative to GDP). This chart shows that a $+100 \mathrm{bps}$ rise in the short rate has a relatively muted effect on the ratio of bank loans to GDP cumulated over four years, although this effect is in the end consistent with models where contractionary monetary policy leads to less demand and/or supply of credit. If anything, the effect is slightly more pronounced when using the Post-WW2 sample although the responses are very similar. Bauer and Granziera (2016) have reported similar patterns based on post-1970 OECD data. Loan contracts are difficult to undo in the short-run relative to the decline of GDP. Therefore, although nominal private credit declines on impact (not shown), the private credit to GDP ratio may take a bit longer to decline.

The takeaway from these impulse responses is clear. An exogenous shock to interest rates has sizable effects on real variables (larger than those measured using conventional VARs), but along the lines predicted by most monetary models with rigidities or frictions. Term structure responses conform very well with standard results in the literature. Nominal variables decline strongly. Perhaps the only variable that appears to be somewhat unresponsive to interest rates is the credit to GDP variable. Loans decline in response to a shock to interest rates, but in the short run their rate of decline matches closely the rate of decline in real economic activity.

For further reference, Figures B.3 and B.4 in Appendix B report the full set of impulse responses out to year 10 after impact for the full and post-WW2 samples respectively. These figures are provided to investigate the neutrality of money in the long-run. We are able to confirm that neutrality cannot be rejected, although the time frame over which neutrality reasserts itself is perhaps quite a bit longer than one might presume. Investment, the more volatile of the components of output, is nearly back to its starting value by year 10 only.

The responses of all nine variables displayed in Figures 2, and B.1, B.3, and B.4 in Appendix B, are consistent with the intuition gained from the long monetary tradition. The differences that we report with that literature are mostly about somewhat stronger effects than previously reported. The next step in our investigation is to assess the stability of these results when we allow them to depend on the state of the economy. 


\section{STATE DEPENDENCE}

In this section we address the possible state dependence of the impulse-response functions by stratifying our analysis of output and inflation responses. In particular, we use indicators for whether the economy is in a boom or slump, in low or high inflation, or in a credit surge or slowdown, to address big issues from the research literature and current policy debates.

Our first stratification in Figure 3 uses the output gap ("boom/slump"). The boom/slump stratification delivers a state-dependent analysis that echoes the analysis in Auerbach and Gorodnichecko (2013b) and Jordà and Taylor (2016) for fiscal policy, namely, that stabilization policy can have different effects in the boom (when the output gap is positive) versus the slump (when the output gap is negative). We measure the gap using a simple low-pass HP filter.

Our second stratification in Figure 4 uses inflation ("high/low"). This links with current debates about the effectiveness of monetary policy in an environment of unusually low inflation. Despite widespread belief in the "divine coincidence" (Blanchard and Galí 2005), the returns to ultra-loose monetary policy are debatable in this setting. Thus, we investigate state dependence based on high/low inflation environments (defined by an annual $2 \%$ CPI inflation rate cutoff).

Our third and final stratification in Figure 5 looks at the growth of credit relative to GDP in the 3 years leading up to the policy intervention, broken down by mortgage versus non-mortgage loans (adjusted for country-specific variation). The data on credit come from Jordà, Schularick, and Taylor (2017), and are now publicly available. 9 This stratification directly speaks to a nascent literature that investigates mechanisms by which household/firm heterogeneity in leverage can affect the effectiveness of monetary policy as discussed in the introduction.

\subsection{State dependence in boom and slump episodes}

In the first set of nonlinear experiments shown in Figure 3 and Table 8, we set the state variable equal to 1 in booms and o in slumps. Booms (slumps) are years when log real GDP per capita is above (respectively, below) its long-run country-specific trend component, as measured by an HP filtered series with a very low-pass setting $\left(\lambda_{H P}=100\right.$, annual).

These results are strongly indicative of an asymmetric macroeconomic response to interest rates. The experiment is always normalized to be $\mathrm{a}+100 \mathrm{bps}$ increase in the short-term rate. This is done to facilitate impulse-response comparisons across states even though, of course, tight policy in a slump is unlikely. The response of real GDP per capita to monetary policy appears to be quite strong in booms (about $-2.5 \%$ by year 4 , full sample), but considerably weaker in slumps (about $-0.5 \%$ by year 4 , full sample).

This difference of nearly $2 \%$ (closer to $1 \%$ Post-WW2) is broadly consistent with Angrist, Jordà, and Kuersteiner (forthcoming), Tenreyro and Thwaites (2016), and Barnichon and Matthes (2016). Evidence of asymmetry is less clear for the inflation response, however. Differences using the full

\footnotetext{
9 http://www.macrohistory.net/data/.
} 
Figure 3: State dependence: monetary policy has a weaker effect on output in slumps

(a) Full sample
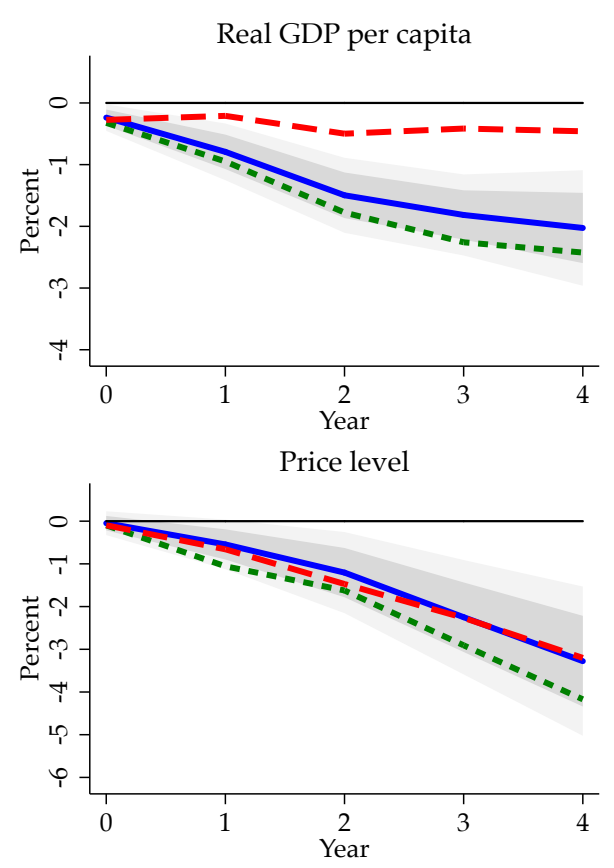

(b) Post-WW2

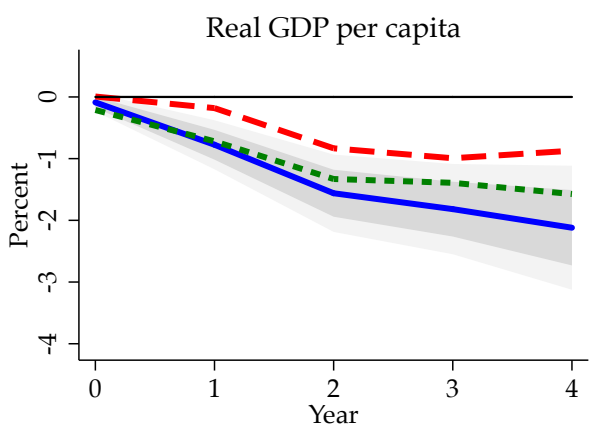

Price level

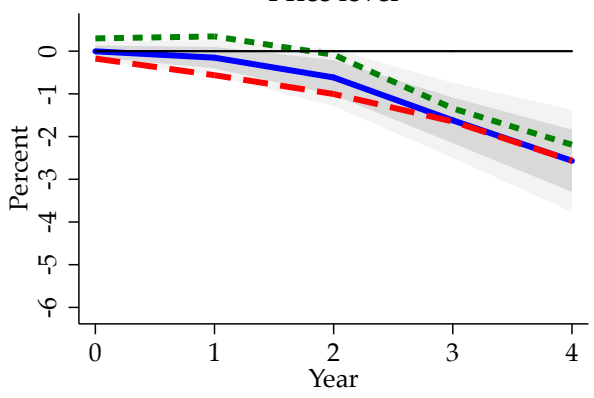

Baseline

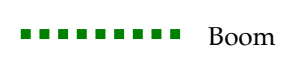

믐ㅁ Slump

Notes: Full sample: 1870-2013 excluding world wars (1914-1919 and 1939-1947). Post-WW2 sample: 19482013. Linear LP-IV estimates displayed with a solid blue line and I S.D. and $90 \%$ confidence bands. Estimates stratified by the boom displayed with a green dotted line whereas estimates in the slumps are displayed with a red dashed line. See text.

Table 8: Cumulative state-dependent multipliers: ratio of real GDP per capita and CPI inflation responses to the corresponding interest rate response (percentage points)

\begin{tabular}{lccc}
\hline \hline & Boom & Slump & Difference \\
\hline Real GDP per capita & -2.7 & -0.4 & -2.3 \\
CPI inflation & -3.4 & -1.7 & -1.7 \\
\hline \hline
\end{tabular}

Notes: Full sample: 1870-2013 excluding world wars (1914-1919 and 1939-1947). The boom (slump) stratification refers to years when log real GDP per capita is above (below) its long-run country-specific trend component. The numbers reported can be interpreted as multipliers, that is, how much would cumulative real GDP per capita (inflation) change in percent (percentage points) on average over the 4 years considered to construct the impulse responses reported in Figure 3. Percent responses are $100 \times \log$. See text. 
sample are very minor and not very different from the average response. The Post-WW2 responses suggest that if the monetary authority tried to stimulate the economy (opposite to what is displayed but consistent with the outlook in many economies today), it would take 2 years before the effects would be felt in prices, although after 4 years the effects would be similar in size to those estimated for the boom state.

As a further check, we calculate average multipliers as the average change in percent (for real GDP per capita) or percentage points (for inflation), relative to the average change in interest rates, all in response to a one percentage point increase in interest rates. This normalization removes differences across states that may arise from differences in the interest rate paths in each state. Table 8 summarizes the values of these multipliers and shows that the stark differences shown in Figure 3 are not driven by differences in the policy response paths.

To sum up, a central bank rate tightening of +100 bps in a boom would have causal effects on output that are strongly contractionary on output going forward. In contrast, a central bank rate loosening of $-100 \mathrm{bps}$ in a slump would have causal effects on output that are, proportionately, only weakly expansionary. However, the effects on prices would be roughly symmetric across the two states. Thus, the "sacrifice ratios" for monetary policy are markedly different, and so are the incentives to pursue pre-emptive monetary policy, in one state versus the other.

\subsection{State dependence in "lowflation" episodes}

Our next set of nonlinear experiments, in Figure 4 and Table 9, concerns the hypothesis that monetary policy may have different effects in times of low inflation, a topic of rising interest since the advanced economies entered an era of "lowflation" as the Great Recession wore on after 2008. To examine this nonlinearity we chose to set an indicator state variable equal to 1 when inflation is low (at or below $2 \%$ ) and o otherwise.

These results could be seen as reinforcing some findings in the previous section concerning differences over the typical output and inflation cycle. Just as in Figure 3, we normalize the responses to $\mathrm{a}+100 \mathrm{bps}$ increase in interest rates, while fully recognizing rates are unlikely to go up when there is lowflation. However, the normalization greatly facilitates the comparison across states. The response of real GDP to monetary policy appears to be quite strong when inflation is above $2 \%$. In that scenario, the cumulated response at year 4 is slightly above $-3 \%$, somewhat stronger than the response in booms reported in figure 3 , which was $-2.5 \%$. However, monetary policy loses most of its traction when the inflation rate dips below the $2 \%$ threshold and economies tip into a lowflation state. In the full sample results, we find that there is no effect on output although in the Post-WW2 sample, the effect on output is somewhat more visible (around $-1 \%$ ).

For completeness, we compute multipliers similar to those reported in Table 8 . That is, we evaluate the average response of real GDP per capita and inflation relative to that of the interest rate path, stratified by whether inflation is above of below two percent. These results are reported in Table 9 and support the results reported in Figure 4. 
Figure 4: State dependence: monetary policy has weaker effects when there is lowflation
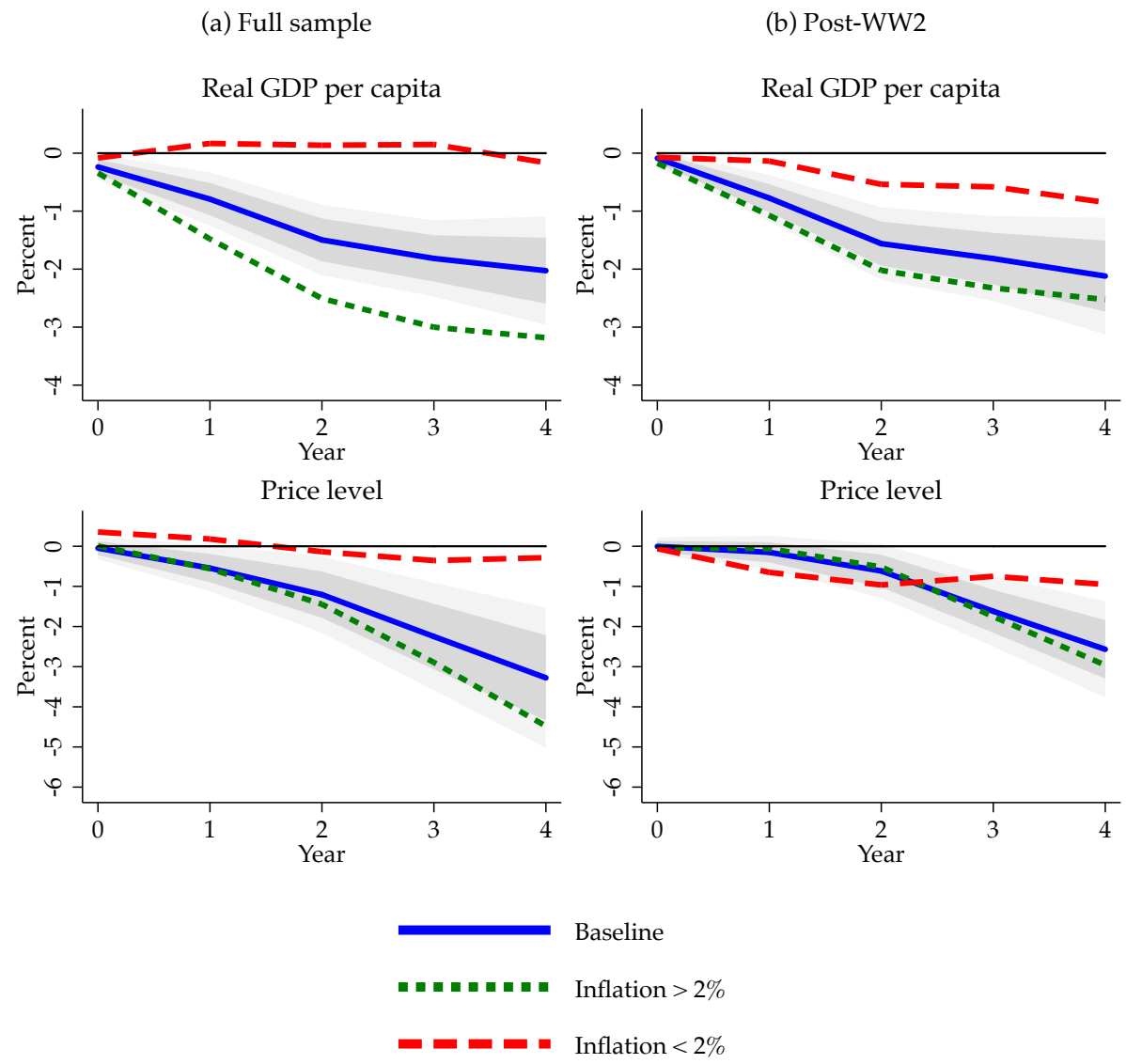

Notes: Full sample: 1870-2013 excluding world wars (1914-1919 and 1939-1947). Post-WW2 sample: 19482013. Linear LP-IV estimates displayed with a solid blue line and I S.D. and 90\% confidence bands. Estimates stratified by the lowflation regime displayed with a red dashed line whereas estimates when inflation is above $2 \%$ are displayed with a green dotted line. See text.

Table 9: Cumulative state-dependent multipliers: ratio of real GDP per capita and CPI inflation responses to the corresponding interest rate response

\begin{tabular}{lccc}
\hline \hline & High inflation & Low inflation & Difference \\
\hline Real GDP per capita & -4.1 & 0.1 & -4.2 \\
CPI inflation & -3.7 & -0.1 & -3.6 \\
\hline \hline
\end{tabular}

Notes: Full sample: 1870-2013 excluding world wars (1914-1919 and 1939-1947). The high (low) inflation stratification refers to years when CPI inflation is above (below) two percent. The numbers reported can be interpreted as multipliers, that is, how much would cumulative real GDP per capita (inflation) change in percent (percentage points) on average over the 4 years considered to construct the impulse responses reported in Figure 4. Percent responses are $100 \times \log$. See text. 
Taken together-the boom/slump and high/low inflation stratification-the historical data are consistent with the scenarios playing out in many advanced economies following the financial crisis. But the financial crisis and theories that try to explain its aftermath often build on what happens when a credit boom goes bust, as we discussed in the introduction (see, e.g., Schularick and Taylor 2012). Thus, the natural next step is to stratify the responses to monetary policy according to credit. This we do in the next subsection by further distinguishing between mortgage and non-mortgage credit growth.

\subsection{State dependence in credit boom and bust episodes}

Our final set of experiments is presented in Figure 5 and Table 10. The results presented in panel A refer to above/below country-specific mean changes in mortgage credit over GDP, whereas panel B focuses instead on changes in non-mortgage credit over GDP.

In previous research (Jordà, Schularick, and Taylor 2016) we have found this distinction to matter and in the context of the theoretical literature, and the limitations of the data, it is the closest we can get to the evaluating household versus firm leverage. Historically, most mortgage credit refers to household rather than commercial real estate borrowing, a trend that has been increasing of late (e.g., the commercial share of mortgages in the U.S. has fallen in the past 40 years from about $40 \%$ to $25 \%$ ). Non-mortgage credit on the other hand, is usually unsecured loans issued to firms rather than households. Hence one can interpret panel A as suggestive that household leverage affects the efficacy of monetary policy in a way that lending to firms does not, as shown in panel B.

In particular, panel A shows that in a period of rapid recent growth in mortgage credit, a $1 \%$ shock in interest rates can depress output by about 3 percentage points more than after a period of below average credit growth, 4 years after intervention. Meanwhile, prices respond much more to interest rates during periods of low recent growth in mortgage credit, relative to other times. In response to the same $1 \%$ interest rate shock discussed earlier, the decline in prices can be about 3 percentage points higher 4 years after intervention.

Meanwhile, panel B shows that there is essentially no difference in the response to monetary policy whether or not non-mortgage credit grows above or below average in the preceding 3 years. Thus, theories that stress heterogeneity coming from consumer leverage appear to find stronger support in our data than theories that rely on firm leverage instead. Furthermore, there seems to be little difference in results including or excluding pre-WW2 data. The effects that we report are fairly stable across eras despite considerable evolution in the financial sector.

As we did in previous sections, we calculate multipliers using the ratio of the average response of real GDP per capita and CPI inflation to the average response of interest rates, using the same stratification as Figure 5. The results for mortgage and non-mortgage credit, as well as total credit are reported in Table 10. Unlike the case of the boom/slump and high/low inflation stratifications, the patterns visible in Figure 5 and the table reveal different information. That is, although Figure 5 suggests that non-mortgage credit generates responses that differ little from the baseline non- 
Figure 5: State dependence: monetary policy and mortgage vs. non-mortgage credit

\section{A: Mortgage credit}

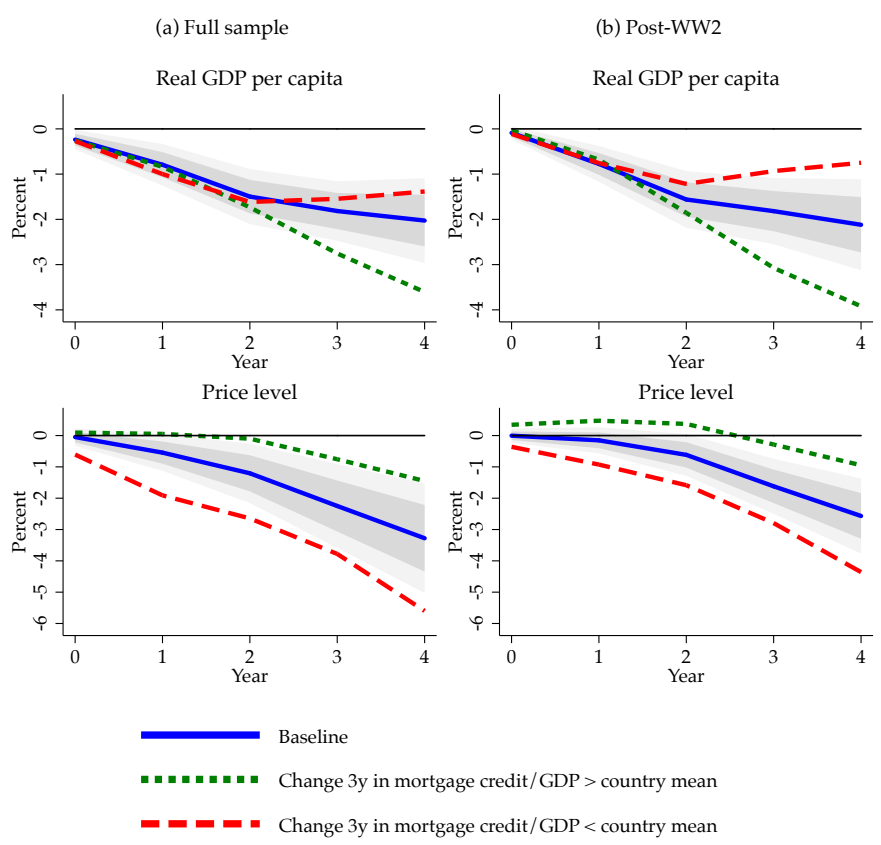

\section{B: Non-mortgage credit}
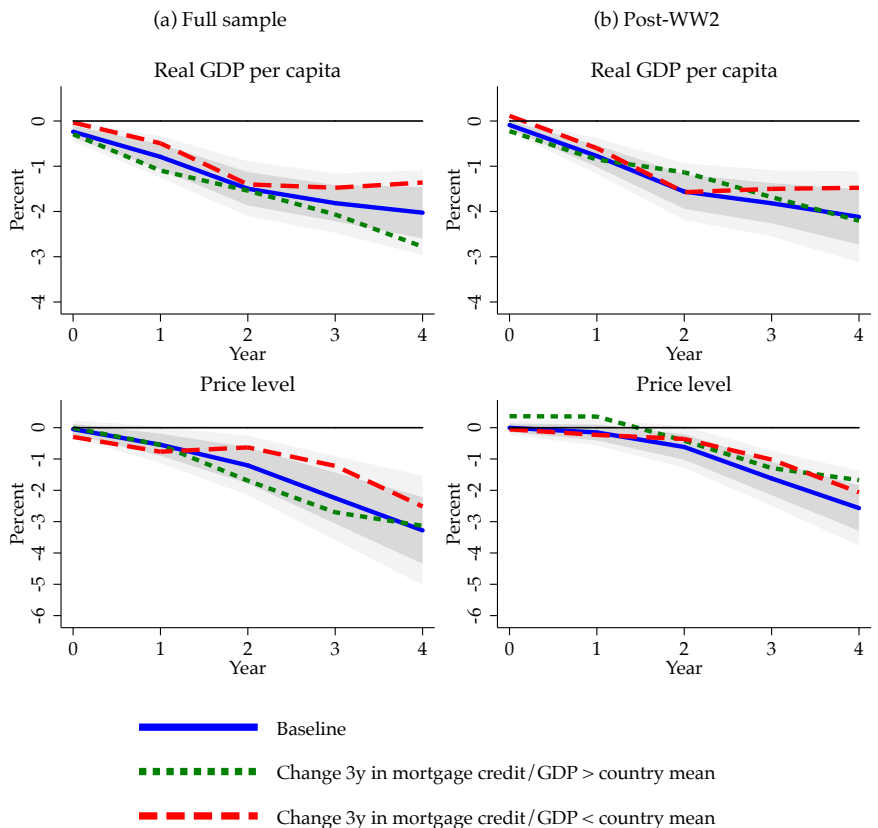

Notes: Full sample: 1870-2013 excluding world wars (1914-1919 and 1939-1947). Post-WW2 sample: 19482013. Linear LP-IV estimates displayed with a solid blue line and I S.D. and 90\% confidence bands. Estimates stratified with below country-average (3y) credit over GDP growth regime displayed with a red dashed line, and above country-average (3y) credit over GDP growth regime displayed with a green dotted line. See text. 
Table 10: Cumulative state-dependent multipliers: ratio of real GDP per capita and CPI inflation responses to the corresponding interest rate response

\begin{tabular}{lccc}
\hline \hline Total credit & High credit & Low credit & Difference \\
\hline Real GDP per capita & -3.7 & -0.6 & -3.1 \\
CPI inflation & -1.5 & -1.9 & 0.4 \\
\hline \hline Mortgage credit & High credit & Low credit & Difference \\
\hline Real GDP per capita & -2.7 & -2.9 & 0.2 \\
CPI inflation & -0.6 & -7.2 & 6.6 \\
\hline \hline Non-mortgage credit & High credit & Low credit & Difference \\
\hline Real GDP per capita & -4.2 & -1.1 & 3.1 \\
CPI inflation & -4.3 & -1.3 & -3.0 \\
\hline \hline
\end{tabular}

Notes: Full sample: 1870-2013 excluding world wars (1914-1919 and 1939-1947). The high (low) credit stratification refers to years when credit growth as a ratio to GDP is above (below) country-specific means. The numbers reported can be interpreted as multipliers, that is, how much would cumulative real GDP per capita (inflation) change in percent (percentage points) on average over the 4 years considered to construct the impulse responses reported in Figure 5. Percent responses are $100 \times \log$. See text.

state dependent response, in part this is explained by differences in the path of interest rates. Moreover, the multipliers reported in Table 1o suggests that there are considerable differences between mortgage and non-mortgage credit stratifications. The effect of interest rates on output differs little depending on whether mortgage credit growth is fast or slow, but the differences are stark with non-mortgage credit. And the effect on inflation goes in the opposite direction.

\section{Conclusion}

The effectiveness of monetary stabilization policy is not only a major policy concern but also an important matter of ongoing controversy among both theoretical and empirical macroeconomists. This paper argues that interest rates can have a considerable effect on macroeconomic outcomes. The source of the attenuation bias that we report suggests that common assumptions, often based on regression control arguments (conditional mean independence), do not provide an adequate basis for identification. Using a quasi-natural experiment in international finance and novel empirical methods, we show why this bias occurs and how to resolve it.

Monetary stabilization policy turns out to be state-dependent, a critical observation in the context of the Great Recession and its aftermath. Policymakers have faced a situation of consistent undershoot relative to their stated objectives and forecasts. A slower than expected growth trajectory has been seen in the U.S. economy, and worse yet in the U.K., Europe, and Japan; and we have seen persistent sub-2\% inflation afflicting all of these economies. Amid worries of deflation risk and secular stagnation, the extensive and unconventional application of monetary policy tools has failed 
to shunt the macroeconomic locomotive onto a faster track. Debate centers on why the central banks got so derailed, and the subsequent lack of policy traction.

Empirical evidence from the largest advanced economy macroeconomic dataset ever assembled shows that all of these travails are, in a sense, nothing new. In conditions where output is weak, inflation is low, or credit is stagnant, the task of stimulating the economy out of its torpor is much more difficult. These challenging conditions have been seen in many western economies for almost a decade, but they were also present in the distant past with similar consequences. Our results therefore have profound implications for how today's monetary models are formulated and applied.

\section{REFERENCES}

Angrist, Joshua D., Guido W. Imbens, and Donald B. Rubin. 1996. Identification of Causal Effects Using Instrumental Variables. Journal of the American statistical Association 91(434): 444-55.

Angrist, Joshua D., Òscar Jordà, and Guido Kuersteiner. Semiparametric Estimates of Monetary Policy Effects: String Theory Revisited. Journal of Business and Economic Statistics. Forthcoming. Auclert, Adrien. 2017. Monetary Policy and the Redistribution Channel. NBER Working Paper 23451.

Auerbach, Alan J., and Yuriy Gorodnichenko. 2013a. Measuring the Output Responses to Fiscal Policy. American Economic Journal: Economic Policy 4(2): 1-27.

Auerbach, Alan J., and Yuriy Gorodnichenko. 2013b. Fiscal Multipliers in Recession and Expansion. In Fiscal Policy After the Financial Crisis edited by Alberto Alesina and Francesco Giavazzi. Chicago: University of Chicago Press, pp. 63-98.

Barnichon, Regis, and Christian Matthes. 2016. Gaussian Mixture Approximations of Impulse Responses and The Non-Linear Effects of Monetary Shocks. CEPR Discussion Paper 11374.

Barro, Robert J., and José F. Ursúa. 2008. Macroeconomic Crises since 1870. Brookings Papers on Economic Activity 39(1): 255-335.

Bauer, Gregory H., and Eleonora Granziera. 2016. Monetary Policy, Private Debt, and Financial Stability Risks. International Journal of Central Banking conference in San Francisco. November 21-22, 2016.

Bernanke, Ben S. and Mark Gertler. 1995. Inside the Black Box: The Credit Channel of Monetary Transmission. Journal of Economic Perspectives 9(4): 27-48.

Blanchard, Olivier, and Jordi Galí. Real Wage Rigidities and the New Keynesian Model. 2007. Journal of Money, Credit and Banking 39(S1): 35-65.

Christiano, Lawrence J., Martin S. Eichenbaum, and Charles L. Evans. 1999. Monetary Policy Shocks: What Have We Learned And To What End? Handbook of Macroeconomics, vol. 1, edited by John B. Taylor and Michael Woodford. Amsterdam: Elsevier, pp. 65-148.

Cloyne, James, Clodomiro Ferreira, and Paolo Surico. 2015. Monetary Policy when Households have Debt: New Evidence on the Transmission Mechanism. CEPR Discussion Paper 11023.

Cloyne, James, and Patrick Hürtgen. 2016. The Macroeconomic Effects of Monetary Policy: A New Measure for the United Kingdom. American Economic Journal: Macroeconomics 8(4): 75-102.

Coibion, Olivier, Yuriy Gorodnichenko, Lorenz Kueng, and John Silvia. 2017. Innocent Bystanders? Monetary Policy and Inequality in the U.S. Journal of Monetary Economics 88: 70-88.

Conley, Timothy G., Christian B. Hansen, and Peter E. Rossi. 2012. Plausibly Exogenous. Review of Economics and Statistics 94(1): 260-72. 
Cox, David R. 1958. Planning of Experiments. New York: John Wiley.

di Giovanni, Julian, Justin McCrary, and Till von Wachter. 2009. Following Germany's Lead: Using International Monetary Linkages to Estimate the Effect of Monetary Policy on the Economy. Review of Economics and Statistics 91(2): 315-31.

di Giovanni, Julian, and Shambaugh, Jay C. 2008. The Impact of Foreign Interest Rates on the Economy: The Role of the Exchange Rate Regime. Journal of International Economics 74(2): 341-61.

Eichenbaum, Martin S. 1992. Comments 'Interpreting the Macroeconomic Time Series Facts: The Effects of Monetary Policy' by Christopher Sims. European Economic Review 36(5): 1001-11.

Faust, Jon, Eric T. Swanson, and Jonathan H. Wright. 2004. Identifying VARs Based on High Frequency Futures Data. Journal of Monetary Economics 51(6): 1107-31.

Gertler, Mark, and Peter Karadi. 2015. Monetary Policy Surprises, Credit Costs, and Economic Activity. American Economic Journal: Macroeconomics 7(1): 44-76.

Gürkaynak, Refet S., Brian Sack, and Eric Swanson. 2005. The Sensitivity of Long-Term Interest Rates to Economic News: Evidence and Implications for Macroeconomic Models. American Economic Review 95(1): 425-36.

Hanson, Michael S. 2004. The "Price Puzzle" Reconsidered. Journal of Monetary Economics 51(7): $1385-1413$.

Hanson, Samuel G., David O. Lucca and Jonathan H. Wright. 2017. Interest Rate Conundrums in the Twenty-First Century. FRBNY Staff Report no. 810.

Iacoviello, Matteo. 2005. House Prices, Borrowing Constraints, and Monetary Policy in the Business Cycle. American Economic Review 95(3): 739-764.

Imbens, Guido W. 2014. Instrumental Variables: An Econometrician's Perspective. NBER Working Paper 19983.

Imbens, Guido W., and Joshua Angrist. 1994. Identification and Estimation of Local Average Treatment Effects. Econometrica 61(2): 467-76.

Ilzetzki, Ethan, Enrique G. Mendoza, and Carlos A. Végh. 2013. How Big (Small?) are Fiscal Multipliers? Journal of Monetary Economics 6o(2): 239-54.

Jordà, Òscar. 2005. Estimation and Inference of Impulse Responses by Local Projections. American Economic Review 95(1): 161-82.

Jordà, Òscar, Moritz Schularick, and Alan M. Taylor. 2015. Betting the House. Journal of International Economics 96(S1): S2-S18.

Jordà, Òscar, Moritz Schularick, and Alan M. Taylor. 2016. The Great Mortgaging: Housing Finance, Crises and Business Cycles. Economic Policy 31(85): 107-152.

Jordà, Òscar, Moritz Schularick, and Alan M. Taylor. 2017. Macrofinancial History and the New Business Cycle Facts. NBER Macroeconomics Annual 2016, no. 31, edited by Martin Eichenbaum and Jonathan A. Parker. Chicago: University of Chicago Press. Forthcoming.

Jordà, Òscar, and Alan M. Taylor. 2016. The Time for Austerity: Estimating the Average Treatment Effect of Fiscal Policy. Economic Journal 126(590): 219-55.

Kaplan, Greg, Benjamin Moll and Giovanni L. Violante. 2016. Monetary Policy According to HANK. NBER Working Paper 21897

Kashyap, Anil K., Owen A. Lamont, and Jeremy C. Stein. 1994. Credit Conditions and the Cyclical Behavior of Inventories. Quarterly Journal of Economics 109(3): 565-593.

Kashyap, Anil K., and Jeremy C. Stein. 1995. The Impact of Monetary Policy on Bank Balance Sheets. Carnegie-Rochester Conference Series on Public Policy 42: 151-19.

Knoll, Katharina, Moritz Schularick, and Thomas Steger. No Price Like Home: Global House Prices, 1870-2012. American Economic Review 107(2): 331-53.

Kuttner, Kenneth N. 2001. Monetary Policy Surprises and Interest Rates: Evidence from the Fed Funds Futures Market. Journal of Monetary Economics 47(3): 523-44. 
Nakamura, Emi, and Jón Steinsson. 2013. High Frequency Identification of Monetary Non-Neutrality. Quarterly Journal of Economics. Forthcoming.

Obstfeld, Maurice, and Kenneth Rogoff. 1995. The Mirage of Fixed Exchange Rates. Journal of Economic Perspectives 9(4): 73-96.

Obstfeld, Maurice, Jay C. Shambaugh, and Alan M. Taylor. 2004. Monetary Sovereignty, Exchange Rates, and Capital Controls: The Trilemma in the Interwar Period. IMF Staff Papers 51(S): 75-108.

Obstfeld, Maurice, Jay C. Shambaugh, and Alan M. Taylor. 2005. The Trilemma in History: Tradeoffs among Exchange Rates, Monetary Policies, and Capital Mobility. Review of Economics and Statistics $87(3): 423-38$.

Obstfeld, Maurice, and Alan M. Taylor. 1998. The Great Depression as a Watershed: International Capital Mobility in the Long Run. In The Defining Moment: The Great Depression and the American Economy in the Twentieth Century, edited by Michael D. Bordo, Claudia D. Goldin, and Eugene N. White. Chicago: University of Chicago Press.

Obstfeld, Maurice, and Alan M. Taylor. 2004. Global Capital Markets: Integration, Crisis, and Growth. Japan-U.S. Center Sanwa Monographs on International Financial Markets. Cambridge: Cambridge University Press.

Ottonello, Pablo, and Thomas Winberry. 2017. Financial Heterogeneity and the Investment Channel of Monetary Policy. University of Michigan. Unpublished.

Owyang, Michael T., Valerie A. Ramey, and Sarah Zubairy. 2013. Are Government Spending Multipliers Greater during Periods of Slack? Evidence from Twentieth-Century Historical Data. American Economic Review 103(3): 129-34.

Quinn, Dennis P., Martin Schindler, and A. Maria Toyoda. 2011. Assessing Measures of Financial Openness and Integration. IMF Economic Review 59(3): 488-522.

Ramey, Valerie A. 2016. Macroeconomic Shocks and Their Propagation. In Handbook of Macroeconomics, Volume 2, edited by J. B. Taylor and H. Uhlig. Amsterdam: Elsevier, pp. 71-162.

Ramey, Valerie A., and Sarah Zubairy. 2014. Government Spending Multipliers in Good Times and in Bad: Evidence from US Historical Data. NBER Working Paper 20719.

Romer, Christina D. and David H. Romer. 1989 Does Monetary Policy Matter? A New Test in the Spirit of Friedman and Schwartz. NBER Macroeconomics Annual 4: 121-70.

Romer, Christina D. and David H. Romer. 2004. A New Measure of Monetary Shocks: Derivation and Implications. American Economic Review 94(4): 1055-84.

Rubin, Donald B. 1974. Estimating Causal Effects of Treatments in Randomized and Nonradomized Studies. Journal of Educational Psychology 66(5): 688-701.

Rubin, Donald B. 1978. Bayesian Inference for Causal Effects: The Role of Randomization. Annals of Statistics 6(1): 34-58.

Rubin, Donald B. 2005. Causal Inference Using Potential Outcomes: Design, Modeling, Decisions. Journal of the American Statistical Association 100(469): 322-331.

Shambaugh, Jay C. 2004. The Effect of Fixed Exchange Rates on Monetary Policy. Quarterly Journal of Economics 119(1): 301-352.

Sims, Christopher A. 1992. Interpreting the Macroeconomic Time Series Facts: The Effects of Monetary Policy. European Economic Review 36(5): 975-1000.

Swanson, Eric T., and John C. Williams. 2014. Measuring the Effect of the Zero Lower Bound on Medium- and Longer-Term Interest Rates. American Economic Review 104(10): 3154-85.

Tenreyro, Silvana, and Gregory Thwaites. 2016. Pushing on a String: US Monetary Policy is Less Powerful in Recessions. American Economic Journal: Macroeconomics. 8(4): 43-74.

Wooldridge, Jeffrey M. 2015. Control Function Methods in Applied Econometrics. Journal of Human Resources 50(2): 420-45. 


\section{APPENDICES}

\section{A. Evaluating the exclusion restriction: general case}

Detailed derivations of the results in Section 3.2 are provided for a panel of data. Denote the generic dimensions of the panel for each subpopulation considered as $N$ for the cross section and $T$ for the time series dimension. Different subpopulations will have different dimensions but, in the interest of clarity, we refrain from using subscripts for now.

In our application, we use the auxiliary subpopulation of floats to correct the IV estimates based on the peg subpopulation for spillover bias. The consistency results are based on $N, T \rightarrow \infty$ for both of these subpopulations. Because we do not need inferential procedures (ours is a robustness check to examine the potential biases from spillover effects) we do not derive the asymptotic distribution of the bias corrected estimator. In other settings, auxiliary information may be available that would allow one to obtain point-identified bias corrections. The derivations provided here could be readily extended to derive the asymptotic distribution.

To simplify the notation, consider the non-state dependent version of expression (5), extended to include potential spillovers:

$$
\begin{aligned}
\Delta r_{i, t} & =a_{i}+z_{i, t} b+x_{i, t} \boldsymbol{g}+\eta_{i, t}, \\
y_{i, t+h} & =\alpha_{i}^{h}+\hat{\Delta} r_{i, t} \beta_{h}+z_{i, t} \phi+\boldsymbol{x}_{i, t} \gamma_{h}+v_{i, t+h} ; \quad h=0,1, \ldots, H .
\end{aligned}
$$

We make standard regularity assumptions about the error processes and assume, in particular, that the following moment conditions hold $E\left(z_{i, t} \eta_{i, t}\right)=E\left(z_{i, t} v_{i, t+h}\right)=0$. That is, $z_{i, t}$ is an exogenously determined valid instrument.

Next, define the projection matrix $M_{i, t}=1-\boldsymbol{w}_{i, t}\left(\boldsymbol{w}_{i, t}^{\prime} \boldsymbol{w}_{i, t}\right)^{-1} \boldsymbol{w}_{i, t}^{\prime}$, where $\boldsymbol{w}$ includes the fixed effects and the $x$, but excludes $z$ and $\Delta r$. Pre-multiplying expression (11) by $M_{i, t}$ allows us to focus on the coefficients of interest, $b, \beta^{h}$, and $\phi$. For example, using this projection matrix, note that the OLS estimator of $b$ is simply

$$
\hat{b}=\left(\frac{1}{N T} \sum_{t=1}^{T} \sum_{i=1}^{N} z_{i, t} M_{i, t} z_{i, t}\right)^{-1}\left(\frac{1}{N T} \sum_{t=1}^{T} \sum_{i=1}^{N} z_{i, t} M_{i, t} \Delta r_{i, t}\right) .
$$

An additional piece of notation will help make the derivations that follow more transparent. Consider the moment condition $E\left(z_{i, t} M_{i, t} \eta_{i, t}\right)=0$. We define the operator

$$
S(z, \eta)=\left(\frac{1}{N T} \sum_{t=1}^{T} \sum_{i=1}^{N} z_{i, t} M_{i, t} \eta_{i, t}\right) \stackrel{p}{\rightarrow} E\left(z_{i, t} M_{i, t} \eta_{i, t}\right)
$$

as a way to refer to the equivalent sample moment condition implied by the population statement. Using this operator and the usual OLS moment conditions, it is easy to see that

$$
\begin{aligned}
& \hat{\beta}_{h}=\frac{S(z, \Delta r) S(z, y(h))-S\left(z^{2}\right) S(\Delta r, y(h))}{S(z, \Delta r)^{2}-S\left(z^{2}\right) S\left(\Delta r^{2}\right)} \\
& \hat{\phi}=\frac{S(z, \Delta r) S(\Delta r, y(h))-S\left(\Delta r^{2}\right) S(z, y(h))}{S(z, \Delta r)^{2}-S\left(z^{2}\right) S\left(\Delta r^{2}\right)} .
\end{aligned}
$$


These moment conditions rely on the usual OLS assumptions $E\left(\Delta r_{i, t} M_{i, t} v_{i, t+h}\right)=0$, and $E\left(z_{i, t} M_{i, t} v_{i, t+h}\right)=0$. However, here we explore what happens to estimators that assume these conditions but where in reality the first moment condition is violated due to the endogeneity of $\Delta r_{i, t}$. In that case, OLS estimates of $\hat{\beta}_{h}$ and $\hat{\phi}$ based on (12) and (13) will be biased.

In particular, we can define the bias term

$$
\hat{\theta}=\frac{S\left(z^{2}\right) S(\Delta r, v(h))}{S(z, \Delta r)^{2}-S\left(z^{2}\right) S\left(\Delta r^{2}\right)} \stackrel{p}{\rightarrow} \theta .
$$

It is then straightforward to show using expressions (12) and (13) that

$$
\begin{aligned}
& \hat{\beta}_{h} \stackrel{p}{\rightarrow} \beta_{h}-\theta, \\
& \hat{\phi} \stackrel{p}{\rightarrow} \phi+b \theta,
\end{aligned}
$$

where we made use of the standard OLS result

$$
\hat{b}=\frac{S(z, \Delta r)}{S\left(z^{2}\right)} \stackrel{p}{\rightarrow} b .
$$

Notice that under the assumptions of the model, this estimator is consistent for $b$. Next, without loss of generality, let $\beta_{h}=\lambda \phi$, for $\lambda$ an unrestricted parameter. Then, it is easy to show that

$$
\hat{\phi}(\lambda)=\frac{\hat{b} \hat{\beta}_{h}+\hat{\phi}}{1+\lambda \hat{b}} \stackrel{p}{\rightarrow} \phi(\lambda) .
$$

In practice the true value of $\lambda$ is unknown. The approach that we follow here is to calculate expression (15) for a range of values of $\lambda \in[\underline{\lambda}, \bar{\lambda}]$. Because $\lambda$ is unknown, we do not attempt to characterize the asymptotic distribution of our spillover corrected estimator.

The next step consists of incorporating $\hat{\phi}(\lambda)$, which is based on the float subpopulation, to correct the IV estimator for the subpopulation of pegs. The control function approach consists in using the usual IV estimator on the following auxiliary expression:

$$
\begin{aligned}
& y_{i, t+h}^{*}=\Delta r_{i, t} \beta_{h}+x_{i, t} \gamma_{h}+u_{i, t+h}, \\
& y_{i, t+h}^{*} \equiv\left(y_{i, t+h}-z_{i, t} \hat{\phi}(\lambda)\right), \\
& \left.\left.u_{i, t+h} \equiv v_{i, t+h}+z_{i, t}(\hat{\phi}(\lambda))-\phi(\lambda)\right)\right) .
\end{aligned}
$$

Consistency of this modified IV estimator only requires the usual consistency conditions of IV estimators applied to the sample of pegs. Notice that if $\hat{\phi}(\lambda) \rightarrow \phi(\lambda)$, then

$$
\left.\left(\frac{1}{N T} \sum_{t=1}^{T} \sum_{i=1}^{N} z_{i, t} M_{i, t} z_{i, t}\right)(\hat{\phi}(\lambda))-\phi(\lambda)\right) \stackrel{p}{\rightarrow} 0 \quad \text { if } \quad E(z M z)<\infty .
$$

This is the condition that, along with the typical IV conditions, ensures consistency for $\hat{\beta}_{h}$ as $N, T \rightarrow \infty$ in both the peg and the float subpopulations. 


\section{B. Robustness checks}

Figures B.1 through B.4 in this appendix contain a series of robustness check which are mentioned in the main text. 
Figure B.1: Full baseline results. Post-WW2 sample
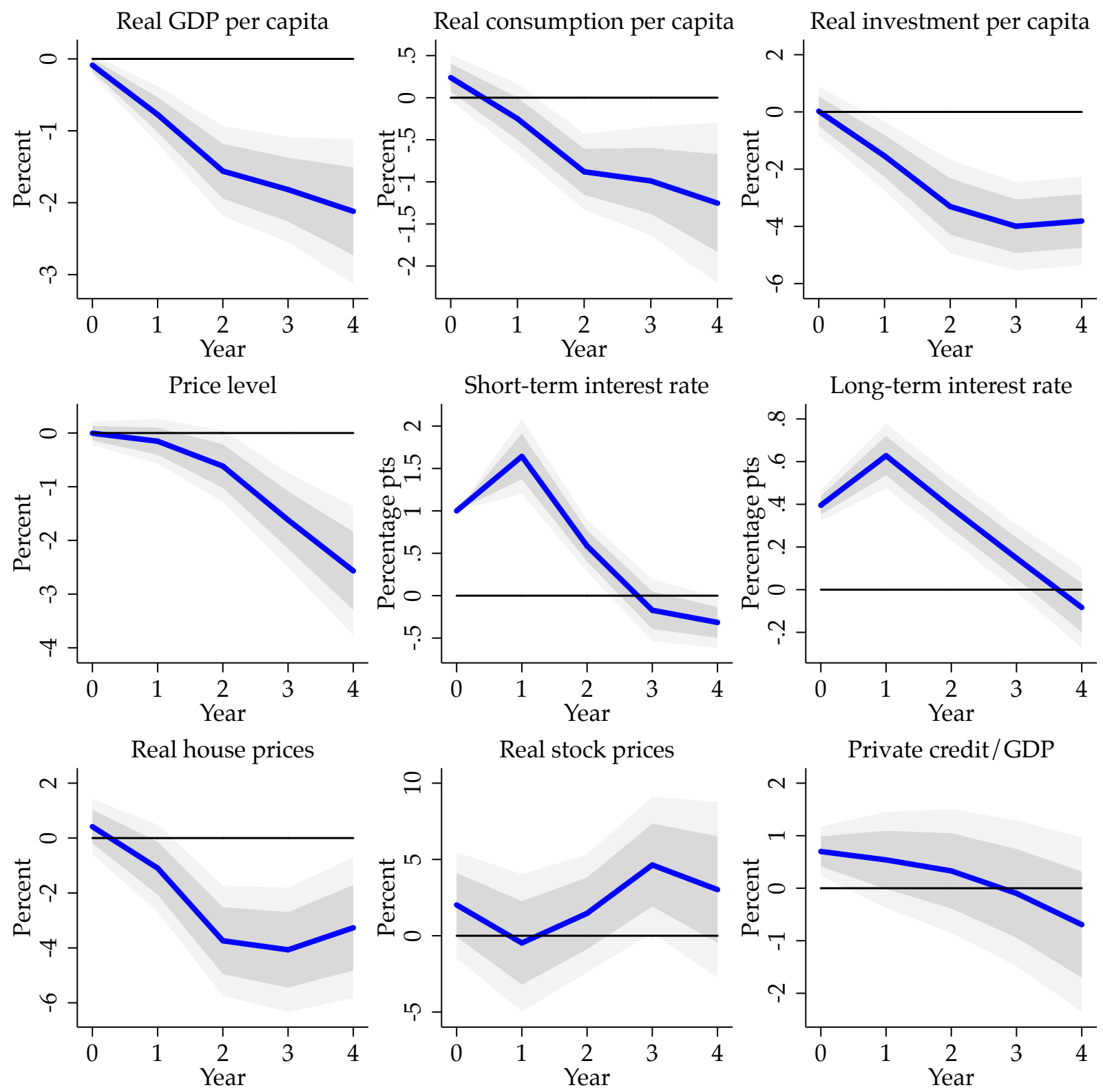

Notes: Post-WW2 sample: 1948-2013. LP-IV estimates displayed with a solid blue line and I S.D. and 90\% confidence bands. See text. 
Figure B.2: Nominal asset price responses to interest rates. Full and post-WW2 samples
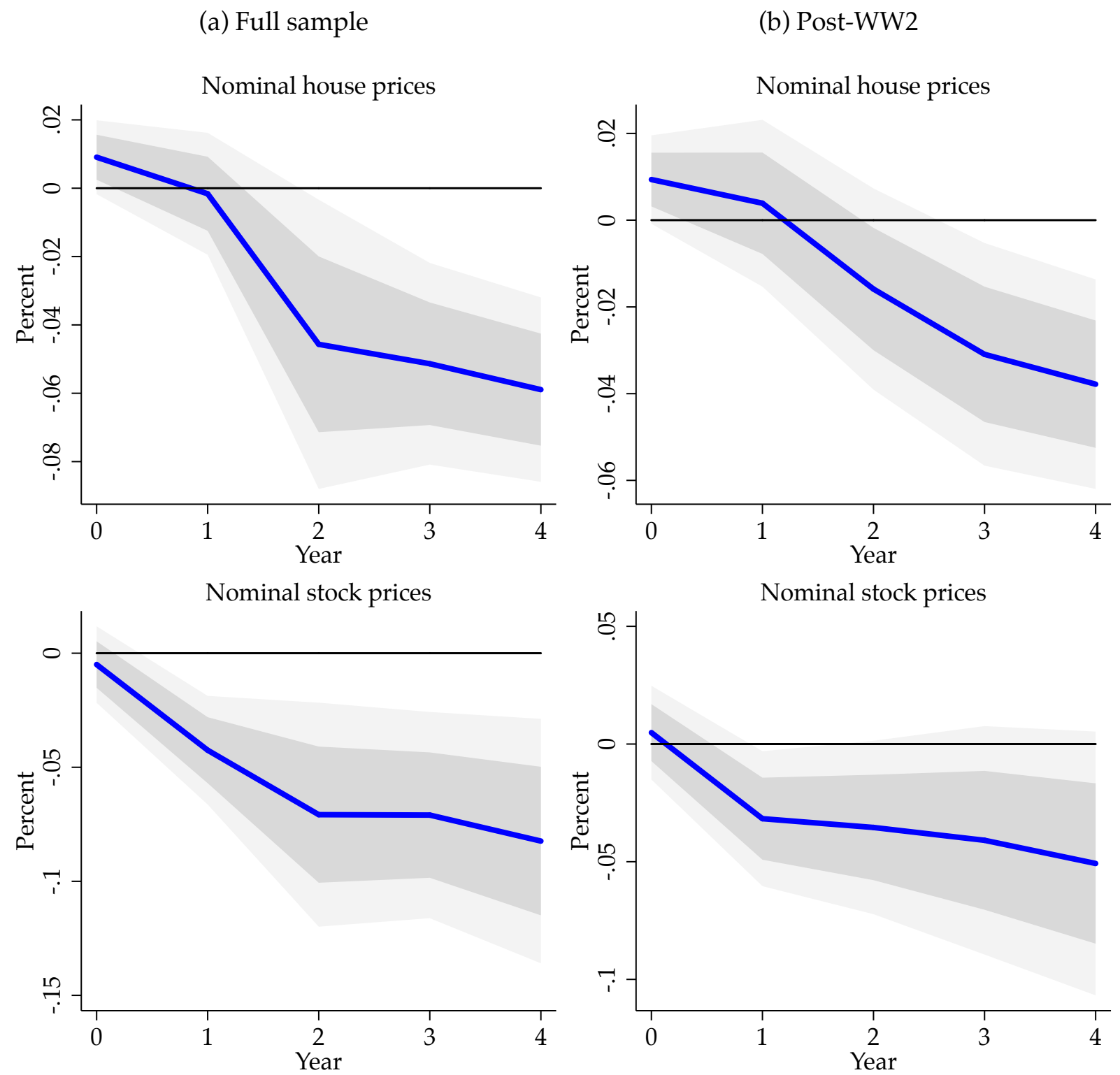

Notes: Full sample: 1870-2013. Post-WW2 sample: 1948-2013. LP-IV estimates displayed with a solid blue line and 1 S.D. and $90 \%$ confidence bands. See text. 
Figure B.3: Full baseline results. Full sample. 10-year horizon
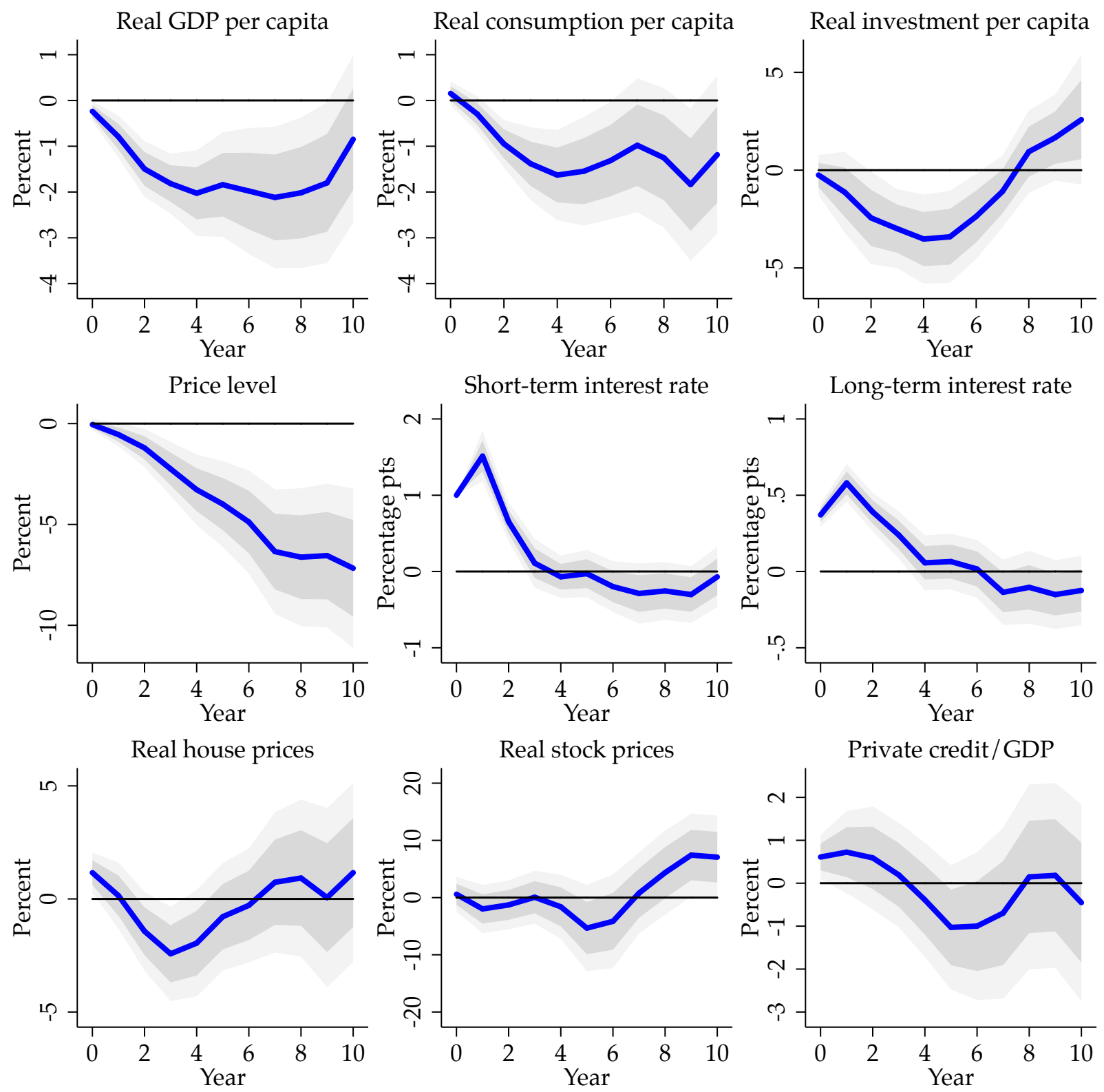

Notes: Full sample: 1870-2013. LP-IV estimates displayed with a solid blue line and 1 S.D. and 90\% confidence bands. See text. 
Figure B.4: Full baseline results. Post-WW2 sample. 10-year horizon
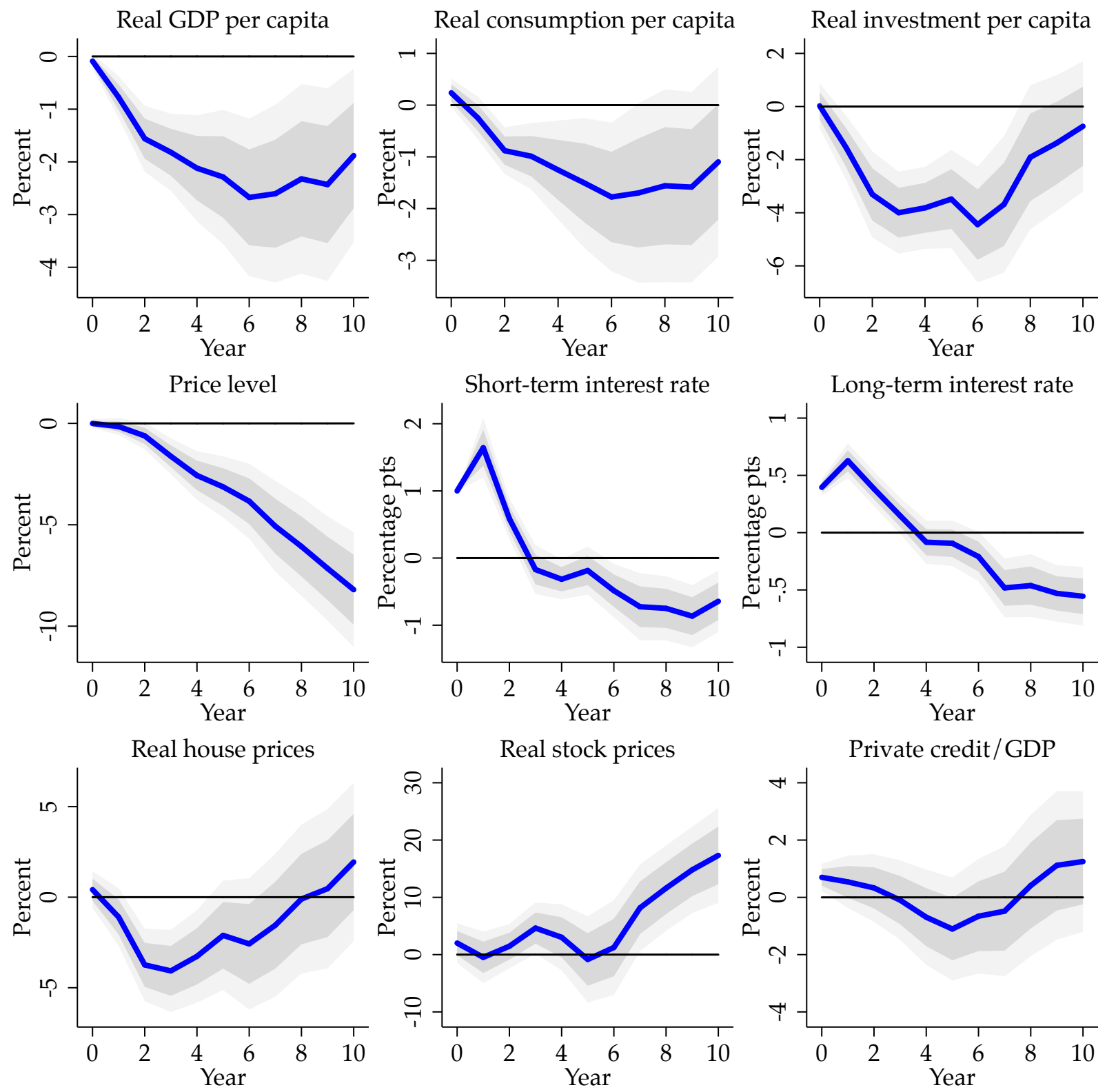

Notes: Post-WW2 sample: 1948-2013. LP-IV estimates displayed with a solid blue line and I S.D. and 90\% confidence bands. See text. 